ARTICLE

\title{
TET1-mediated DNA hydroxymethylation regulates adult remyelination in mice
}

Sarah Moyon ${ }^{1 凶}$, Rebecca Frawley ${ }^{1}$, Damien Marechal ${ }^{1}$, Dennis Huang ${ }^{1}$, Katy L. H. Marshall-Phelps ${ }^{2}$, Linde Kegel ${ }^{2}$, Sunniva M. K. Bøstrand (1) 2, Boguslawa Sadowski 3,4,5, Yong-Hui Jiang ${ }^{6}$, David A. Lyons (1) ${ }^{2}$, Wiebke Möbius (1D) ${ }^{3,4,5} \&$ Patrizia Casaccia (1D) ${ }^{1,7 凶}$

The mechanisms regulating myelin repair in the adult central nervous system (CNS) are unclear. Here, we identify DNA hydroxymethylation, catalyzed by the Ten-ElevenTranslocation (TET) enzyme TET1, as necessary for myelin repair in young adults and defective in old mice. Constitutive and inducible oligodendrocyte lineage-specific ablation of Tet1 (but not of Tet2), recapitulate this age-related decline in repair of demyelinated lesions. DNA hydroxymethylation and transcriptomic analyses identify TET1-target in adult oligodendrocytes, as genes regulating neuro-glial communication, including the solute carrier $(S / C)$ gene family. Among them, we show that the expression levels of the $\mathrm{Na}^{+} / \mathrm{K}^{+} / \mathrm{Cl}^{-}$transporter, SLC12A2, are higher in Tet1 overexpressing cells and lower in old or Tet1 knockout. Both aged mice and Tet1 mutants also present inefficient myelin repair and axo-myelinic swellings. Zebrafish mutants for s/c12a2b also display swellings of CNS myelinated axons. Our findings suggest that TET1 is required for adult myelin repair and regulation of the axonmyelin interface.

\footnotetext{
${ }^{1}$ Neuroscience Initiative Advanced Science Research Center, New York, NY, USA. ${ }^{2}$ Centre for Discovery Brain Sciences, Edinburgh, UK. ${ }^{3}$ Department of Neurogenetics, Göttingen, Germany. ${ }^{4}$ Electron Microscopy Core Unit, Max-Planck-Institute of Experimental Medicine, Göttingen, Germany. ${ }^{5}$ Center Nanoscale Microscopy and Molecular Physiology of the Brain (CNMPB), Göttingen, Germany. ${ }^{6}$ Department of Neurobiology and Pediatrics, Duke University School of Medicine, Durham, NC, USA. ${ }^{7}$ Program of Biology and Biochemistry, The Graduate Center of The City University of New York, New York, NY, USA.

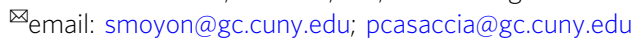


$\mathrm{N}$ ew myelin formation in the adult brain is critical for repair of damaged or lost myelin, which is impaired in several neurological and psychiatric disorders ${ }^{1-4}$. Myelin is the specialized membrane of oligodendrocytes (OLs), whose differentiation from oligodendrocyte progenitor cells (OPCs) results from the interplay of transcription factors and epigenetic regulators that can be influenced by diverse external stimuli ${ }^{5,6}$. Most of these mechanisms have been studied in the context of developmental myelination or in primary cultured cells ${ }^{7-10}$. However, the epigenetic marks in each cell type, are affected by external conditions, age and disease states $3,11-15$. We and others have reported the role of several epigenetic marks at distinct stages of oligodendrocyte cell lineage and discussed the importance of specific chromatin modulators for developmental myelination $8,10,16,17$ and remyelination ${ }^{18,19}$. In particular, DNA methylation, catalyzed by DNA methyltransferases (DNMTs), is the single most significative epigenetic mark predictive of biological age ${ }^{14-20}$. We recently reported an age-dependent role of DNMT1 regulating proliferation and differentiation of neonatal OPCs (nOPCs) ${ }^{16}$ and having only minor effects on the differentiation of adult OPCs (aOPCs) during myelin repair ${ }^{19}$. However, our genome-wide DNA methylation dataset was obtained using bisulfite-conversion sequencing ${ }^{16}$, and therefore could not distinguish between two distinct modifications on cytosine residues, with opposing transcriptional outcomes: DNA methylation $(5 \mathrm{mC})$, an epigenetic modification generally associated with transcriptional repression, and DNA hydroxymethylation $(5 \mathrm{hmC})$, mainly associated with transcriptional activation ${ }^{21,22}$. Together with the distinct roles of DNMTs in developmental myelination and adult remyelination, this raised the question on the genome-wide distribution and functional role of DNA hydroxymethylation in adult myelin repair, that is addressed in this study.

DNA hydroxymethylation refers to the oxidation of methylated cytosine residues in the DNA $(5 \mathrm{mC})$, in a multi-step reaction catalyzed by enzymes called Ten-Eleven Translocation

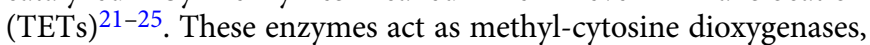
which convert a hydrogen atom at the C5-position of cytosine to a hydroxymethyl group ( $5 \mathrm{hmC}$ ), through oxidation of $5 \mathrm{mC}^{23-25}$. As such, this reaction has been suggested to serve as an intermediate step to promote DNA demethylation and favor gene expression $21,22,24-27$. The TET family includes proteins that are particularly enriched in brain tissue and differentially expressed in neuronal and glial cells $s^{21,26-28}$. In neuronal progenitors, TETs are necessary for their differentiation during cortical development $^{29}$, and later for axonal growth and functional neuronal circuits formation ${ }^{30,31}$. In glial cells, although their expression has been reported in cultured glial cells ${ }^{28}$ and dysregulated in glioblastomas ${ }^{32}$, a thorough molecular and functional analysis of DNA hydroxymethylation in the adult brain and in myelin repair is lacking.

Here, we combined unbiased sequencing approaches and in silico data analysis, with immunohistochemical and phenotypic characterization of lineage specific constitutive and inducible mouse mutants to identify TET1 as an enzyme responsible for the expression of genes regulating the axon-myelin interface during myelin repair.

\section{Results}

Age-dependent DNA hydroxymethylation during myelin regeneration. To start characterizing the distinct contribution of DNA methylation and hydroxymethylation to spinal cord OLIG2 + oligodendroglial cells at postnatal day 7 (P7) and adulthood (P60), we assessed nuclear immunoreactivity to antibodies specific for the DNA methylation mark 5 methylcytosine $(5 \mathrm{mC})$
(Fig. 1a, b) or for the DNA hydroxymethylation mark 5 hydroxymethylcytosine (5hmC) (Fig. 1c, d). The levels of immunoreactivity were expressed as the ratio of intensity of either $5 \mathrm{mC}$ or $5 \mathrm{hmC}$ to the nuclear area of OLIG $2+$ cells (expressed in pixels $/ \mu \mathrm{m}^{2}$ ) and the proportion of OLIG $2+$ cells with low $\left(<5\right.$ pixels $\left./ \mu \mathrm{m}^{2}\right)$, medium (between 5 and 10 pixels $\left./ \mu \mathrm{m}^{2}\right)$ and high $\left(>10\right.$ pixels $\left./ \mu \mathrm{m}^{2}\right)$ was calculated. The proportion of OLIG $2+$ cells with high levels of DNA methylation increased from $4.33 \pm 1.23$ in the neonatal spinal cord to $28.84 \pm 3.75 \%$ in the adult tissue (Fig. 1b). The time-dependent increase in the proportion of OLIG2 + cells with high levels of DNA hydroxymethylation was even more striking, ranging from $1.84 \pm 1.03 \%$ in the neonatal spinal cord to $35.50 \pm 8.12 \%$ in the adult tissue (Fig. 1d). Since hydroxymethylation requires the presence of a methyl group on the DNA as substrate, the higher proportion of OLIG $2+$ cells with high levels of $5 \mathrm{mC}$ and $5 \mathrm{hmC}$ in the adult compared to the neonatal spinal cord, set the premise for a deeper investigation on the functional role of this mark in adult myelin formation.

As a major function of adult OPCs is myelin repair in response to a demyelinating injury, we opted to use the lysolecithin (LPC)induced model of demyelination in the spinal cord of young (P60) and old (P540) adult mice (Fig. 1e). The selection of this experimental model was due to the fact that the temporal pattern of demyelination and remyelination has been extensively reported to decline with age $\mathrm{e}^{33-38}$. Consistent with previous reports 37 , remyelination after LPC injection was efficient in young P60 adult mice 21 days after lesion $(21 \mathrm{dpl})$, and impaired in old P540 mice, as indicated by the lower number of remyelinated axons (Fig. 1f, g). The age-dependent decline in remyelination was also assessed on cryosections, using Fluoromyelin staining at 7, 14, and 21dpl (Supplementary Fig. 1a-d). In young adults, the intensity of the Fluoromyelin staining gradually recovered after lesion, reaching the same levels of intensity as unlesioned white matter tracts by $21 \mathrm{dpl}$ (Supplementary Fig. 1a, b), while the recovery was delayed and less effective in older mice (Supplementary Fig. 1c, d). The successful recovery in young mice was preceded by a progressive increase in the percentage of OLIG2 + cells with high levels of $5 \mathrm{hmC}$ starting at $14 \mathrm{dpl}$ (Fig. $1 \mathrm{~h}$ and Supplementary Fig. 1e). Old mice, in contrast, showed a delayed and impaired response, characterized by a lower percentage of OLIG $2+$ cells with high $5 \mathrm{hmC}$ (Fig. 1i), although the overall density of OLIG2 + cells remained constant between young and old mice (Supplementary Fig. 1f). As previously described, adult OPC in young and old mice started proliferating in response to a demyelinating lesion, although the response was less prominent in old mice (Supplementary Fig. 1g). Differentiation of OLIG2 + cells into CC1 + oligodendrocytes, was also much more pronounced in young mice (Fig. 1j), than old ones (Fig. 1k). Together, these data support an overall agedependent decline of DNA hydroxymethylation and remyelination.

TET1 and TET2 are the most abundant isoforms in the oligodendrocyte lineage, although only TET1 shows an agedependent decline. DNA hydroxymethylation is catalyzed by the Ten-Eleven Translocation (TET) family of enzymes, which includes TET1, TET2, and TET3. We therefore started characterizing the presence of these distinct isoforms by performing immunohistochemistry in cryosections of adult spinal cord (Fig. 2a) and corpus callosum (Fig. 2b). Of the three enzymes, TET 1 and TET 2 showed clear immunoreactivity in OLIG2 + cells in the adult spinal cord, with TET3 being detected only in a very small percentage of OLIG 2 + cells (Fig. $2 \mathrm{c}$ ). To further address the impact of aging on the levels of these enzymes, we sorted OPCs from neonatal (P5), young (P60) and old (P540) Pdgfra-H2BEGFP reporter mice, and used a single-cell suspension capture method, based on microfluidics (C1 Fluidigm), to amplify transcripts by 


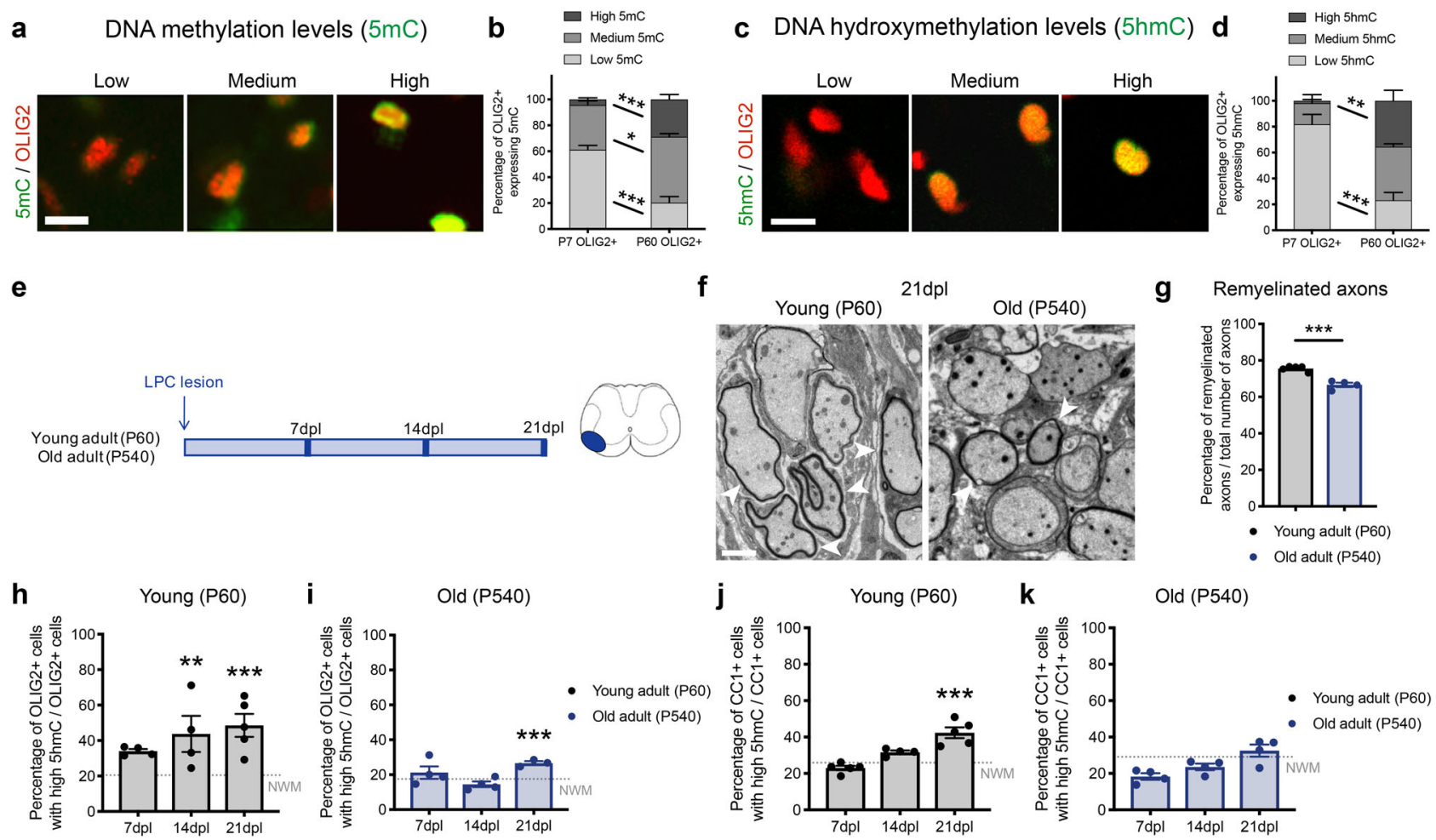

Fig. 1 Age-dependent DNA hydroxymethylation during new myelin formation. a Nuclear immunoreactivity specific for 5 methylated cytosine ( $5 \mathrm{mC}$, green) and OLIG2 (red) in adult mouse spinal cord sections. Scale bar $=10 \mu \mathrm{m}$. b Bar graphs showing the relative proportion of OLIG2 + cells with low, medium, or high levels of $5 \mathrm{mC}$ immunoreactivity in the neonatal (P7) and adult (P60) spinal cord. Error bars represent SEM for $n=4$ mice $\left({ }^{\star} p<0.05\right.$ and ${ }^{\star \star \star} p<0.001$, two-way ANOVA, for age and $5 \mathrm{mC}$ immunoreactivity). c Nuclear immunoreactivity specific for hydroxymethylated cytosines (5hmC, green) and for OLIG2 (red) in adult mouse spinal cord sections. Scale bar $=10 \mu \mathrm{m}$. d Bar graphs showing the relative proportion of OLIG2 + cells with low, medium, or high levels of $5 \mathrm{hmC}$ immunoreactivity in the neonatal (P7) and adult (P60) spinal cord. Error bars represent SEM for $n=4$ mice ${ }^{\star \star} p<0.01$ and ${ }^{\star * \star} p<0.001$, two-way ANOVA, for age and $5 \mathrm{hmC}$ immunoreactivity). e Schematic experimental timeline of lysolecithin lesion experiment in young and old mice. f Electron micrographs of lesioned spinal cord sections from young (P60) and old (P540) mice at 21 days post-lesion (21dpl). Remyelination in young and old adult samples shown by white arrowheads. Scale bar $=5 \mu \mathrm{m}$. $\mathbf{g}$ Data indicate the average remyelinated axons in young and old spinal cord 21dpl. Error bars represent SEM for $n=5$ young mice and $n=4$ old mice $\left({ }^{\star \star \star} p=0.0002\right.$, Student's $t$ test two-tailed). $\mathbf{h}$, i Quantification of the percentage of OLIG2 + cells with high levels of $5 \mathrm{hmC}$ in spinal cord lesions at $7 \mathrm{dpl}, 14 \mathrm{dpl}$, and $21 \mathrm{dpl}$, in young (h) and old (i) mice. Dotted line indicates the relative percentage of OLIG2 + cells with high level of $5 \mathrm{hmC}$ in unlesioned white matter tracts (NWM). Data represent the average of 3 sections/mouse. Error bars represent SEM for $n=5$ young mice and $n=4$ old mice ${ }^{\star \star} p<0.01$ and ${ }^{\star \star \star} p<0.001$, one-way ANOVA, for time after lesion). $\mathbf{j}, \mathbf{k}$ Quantification of the percentage of $\mathrm{CC} 1+$ cells with high level of $5 \mathrm{hmC}$ in spinal cord lesions in young (j) and old (k) mice analyzed at $7 \mathrm{dpl}$, 14dpl, and $21 \mathrm{dpl}$. Dotted line indicates the relative percentage of $\mathrm{CC} 1+$ cells with high level of $5 \mathrm{hmC}$ in unlesioned white matter tracts (NWM). Data points indicate the average 3 sections/mouse. Error bars represent SEM for $n=5$ young mice and $n=4$ old mice ( ${ }^{\star \star} p<0.001$, one-way ANOVA, time after lesion).

real-time quantitative PCR (rt-qPCR) of the three preparations (Fig. 2d). Transcripts for Tet1 (Fig. 2e) and the percentage of TET1 expressing OLIG2 + cells (Fig. 2f) were the most dramatically decreased by aging. Tet 2 transcript levels and the percentage of TET2 expressing OLIG2 + cells, in contrast, were only minimally impacted by age (Fig. 2e, f). The age-dependent differences in TET1 (Supplementary Fig. 2a-d), but not TET2 (Supplementary Fig. 2e-h) levels, persisted in the lesioned adult spinal cord during repair from demyelinating lysolecithin injections (Supplementary Fig. 2). Together, these findings identify the levels of TET1, and not of TET2, to decline with age, concurrently with the levels of $5 \mathrm{hmC}$ in oligodendroglial lineage cells.

Constitutive or inducible ablation of Tet1 in OPCs mimics the events leading to defective myelin regeneration detected in old mice. As aging resulted in the progressive decline of Tet1, we asked whether a lineage specific constitutive conditional knockout for Tet 1 would mimic the inefficient remyelination phenotype observed in old mice. We therefore crossed Olig1-cre mice ${ }^{39}$ with the Tet1-flox line (gift from Pr. Yong-Hui Jiang) ${ }^{40}$ (Fig. 3) or with the Tet2-flox line $e^{41}$ to further address the specificity of the isoform (Supplementary Fig. 3). Both crosses generated truncated and catalytically inactive TET1 or TET2 isoforms (see Methods for details). Survival, body size, and weight of Olig1 ${ }^{\text {cre } /+} ;$ Tet $1^{f l / f l}$ (Tet1 mutants) or Olig $1^{\text {crel }+} ;$ Tet $2^{f l f l}$ (Tet2 mutants) mice did not differ from their respective controls $\left(\mathrm{Olig} 1^{+/+} ;\right.$Tet $1^{f l / f l}$ and Olig $1^{+/+} ;$Tet $2^{f l f l}$ ) (Fig. 3a-c, Supplementary Fig. 3a-c) and no overt motor phenotype was detected.

Immunohistochemistry validated the cell lineage specificity of Tet1 (Supplementary Fig. 4a) or Tet2 (Supplementary Fig. 4b) ablation in OLIG2 + cells, and not in ISLET1 + neurons (Supplementary Fig. 4c, d) or GFAP + astrocytes (Supplementary Fig. 4e, f). We also validated the absence of any compensatory upregulation of other TET isoforms in each of the mutants, compared to controls (Fig. 3d, Supplementary Fig. 3d).

Quantification of immunostained spinal cord (Fig. 3e, h) from Tet1 mutants did not reveal any difference in OLIG2 + or CC1 + cell density (Fig. 3f) or in the extent of MBP + areas (Fig. 3g), compared to controls. Quantification of myelin protein levels in P60 spinal cord extracts did not show significant differences between the two genotypes (Fig. 3i, j). Ultrastructural analysis of 
a

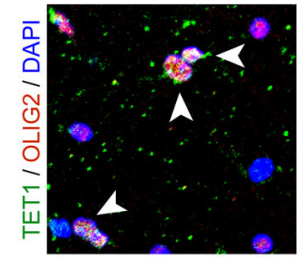

b

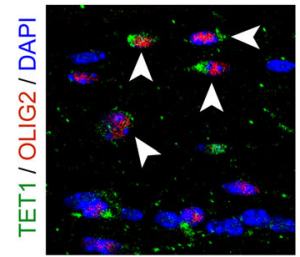

d

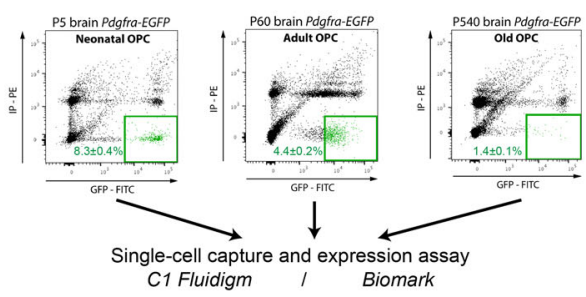

P60 spinal cord WM

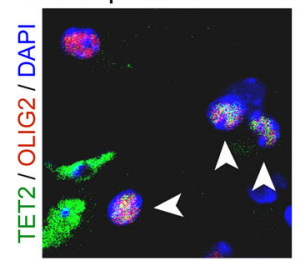

P60 corpus callosum

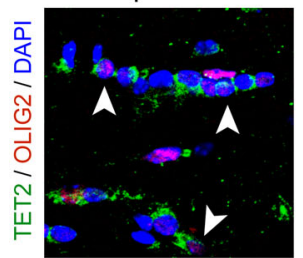

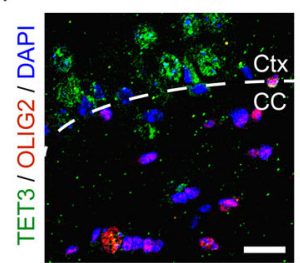

e

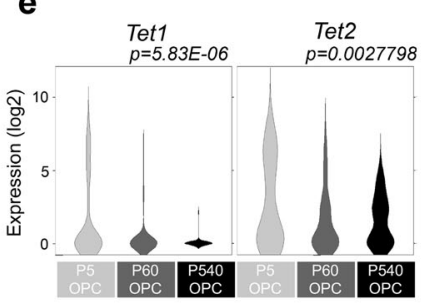

Spinal cord WM
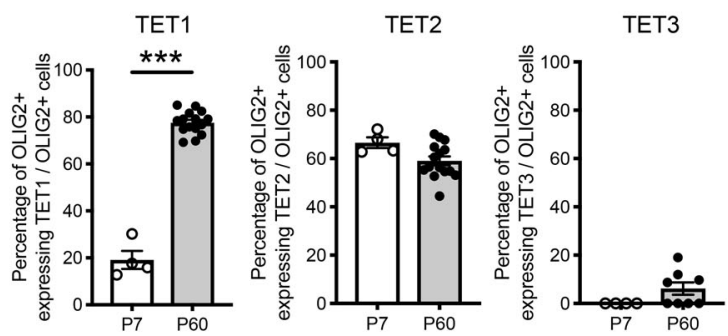

f
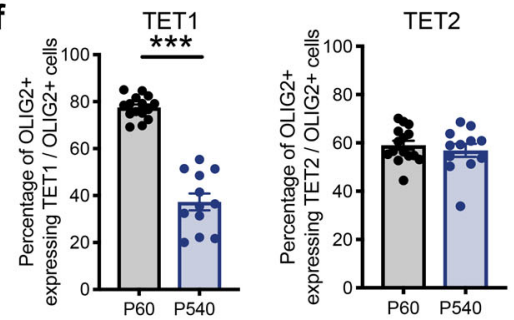

Fig. 2 TET1 and TET2 are the most abundant isoforms in OLIG2 + cells in the adult spinal cord, with only TET1 displaying an age-dependent decline. a, b Representative confocal images of coronal spinal cord (a) and brain (b) sections from adult mice (P60) stained with antibodies specific for the indicated TET isoforms (green) and for OLIG2 (in red). White arrowheads indicate co-labeled cells. Scale bar $=50 \mu \mathrm{m}$. c Percentage of OLIG2 + cells expressing TET1, TET2, or TET3 in postnatal P7 and adult P60 spinal cord. Error bars represent SEM for $n=4$ (for neonates) and $n=22$ (for adult) samples ( ${ }^{\star \star *} p<0.001$ for TET1, $p=0.0640$ for TET2, $p=0.1281$ for TET3, Student's $t$ test two-tailed). d Representative fluorescence-activated cell sorting plots of oligodendrocyte progenitor cells isolated from Pdgfro-H2BEGFP reporter mice at neonatal (P5, nOPC), adult (P60, aOPC), and old (P540, oOPC) age. Single-cells were captured and RNA extracted using microfluidics (C1Fluidigm), coupled to RT-qPCR for single-cells, using Biomark. e Violin plots of Tet1 and Tet2 in nOPC $(n=61)$, aOPC $(n=76)$, and OOPC $(n=51)$ reveal a significant and sharp age-dependent decline of Tet1 and to a much lesser extent of Tet2 expression. Data represent log2 expression, derived from Ct (one-way ANOVA, factors age). f Bar graphs show the percentage of TET1 or TET2 expressing OLIG2+ cells in young and old spinal cord sections. Average counts in 3-4 sections per mouse for $n=22$ (young) and $n=6$ (old) mice, error bars represent SEM ( ${ }^{\star \star *} p<0.001$ for TET1, $p=0.5050$ for TET2, Student's $t$ test two-tailed).

ventral white matter spinal cord sections revealed the same number of myelinated fibers (Fig. 3k, l) and g-ratio (Fig. $3 \mathrm{~m}$ ) in control and Tet 1 mutants. Similar cell density (Fig. 3n, o) and extent of MBP immunoreactivity (Fig. 3p) were detected in the corpus callosum of Tet1 mutants compared to controls, suggesting no regional differences. Tet 2 mutants did not reveal any difference in myelin content compared to controls (Supplemental Fig. 3e-j).

To further ascertain that lack of Tet 1 did not impact the critical period of developmental myelination, we conducted immunohistochemical analysis of spinal cord sections at earlier developmental time points (postnatal day 14, P14) (Supplementary Fig. 5a). Also, at this time point, the density of OLIG2 + cells and $\mathrm{CC} 1+$ oligodendrocytes (Supplementary Fig. 5b) and the extent of immunoreactive MBP areas (Supplementary Fig. 5c) were similar between Tet 1 mutants and controls. Those findings were further validated by electron microscopy on postnatal day 14 spinal cords (Supplementary Fig. 5d, e) and optic nerves (Supplementary Fig. 5g, h) from controls and Tet1 mutants, which revealed similar numbers of myelinated axons (Supplementary Fig. 5e, h) and similar g-ratio (Supplementary Fig. 5f, i) in mice of the two genotypes. Overall, we conclude that adult myelination was not impacted by the loss of Tet 1 or Tet 2 during development.

To address the functional consequences of Tet 1 ablation on myelin repair, we then induced demyelination by LPC injection in the spinal cord of mice with either constitutive (Olig1-cre; Tet1- flox) (Fig. 4a) or tamoxifen-inducible ablation $\left(P d g f r a-c r e E R^{(T)}\right.$; Tet1-flox) of Tet1 in oligodendrocyte progenitors ${ }^{42}$ (Fig. $4 \mathrm{n}$ ). Constitutive Tet2 mutants (Olig1-cre;Tet2-flox) were used as control for specificity (Fig. 4a). At $14 \mathrm{dpl}$, a lower proportion of OLIG2 + with high 5hmC (Fig. 4b, c), was detected within the area surrounding the lesion in constitutive Tet1 mutants compared to controls, while no difference was detected in the Tet 2 mutants (Fig. 4d, e). Constitutive Tet1 mutant mice with defective DNA hydroxymethylation also showed impaired myelin regeneration compared to controls (Fig. 4f, g and Supplementary Fig. 6a), while Tet2 mutants were virtually indistinguishable from wild-type mice (Fig. 4h, i and Supplementary Fig. 6a). Impaired remyelination in the Tet 1 mutants was validated by electron microscopy (Fig. 4j), which revealed fewer remyelinated axons (Fig. 4k) but unaltered g-ratio (Fig. 4l), compared to controls. The inefficient remyelination in the Tet 1 mutants could not be explained by defective proliferation (Supplementary Fig. 6b) or decreased early differentiation, as the percentage of OLIG $2+$ and $\mathrm{CC} 1+$ cells was the same in mutants and controls at 14dpl (Supplementary Fig. 6c). We therefore reasoned that the changes detected during the repair process were likely consequent to altered gene expression in differentiating $\mathrm{CC} 1+$ oligodendrocytes, due to impaired DNA hydroxymethylation (Fig. 4m).

To rule out that the observed phenotype could be linked to any residual effect of Tet1 loss-of-function during developmental myelination, we repeated these critical experiments in the tamoxifen-inducible lineage-specific Pdgfra-creER ${ }^{(T)}$; Tet1-flox 
a

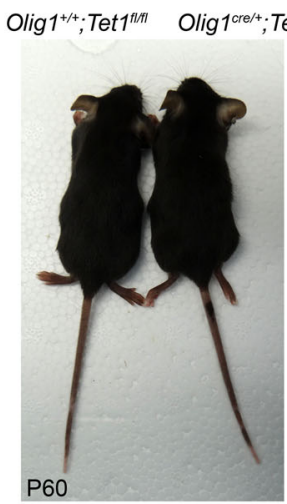

b

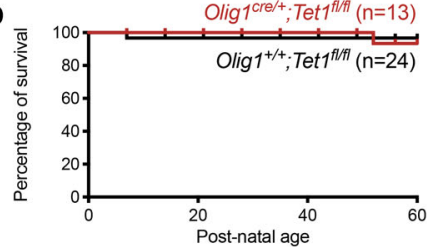

c

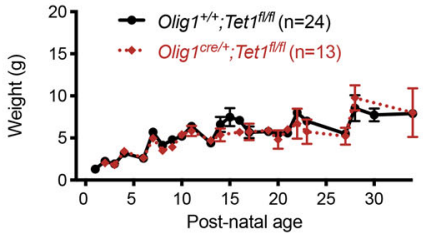

d

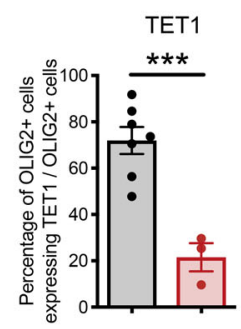

P60 corpus callosum

TET2

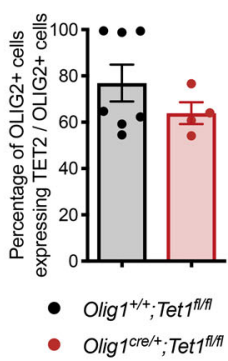

TET3

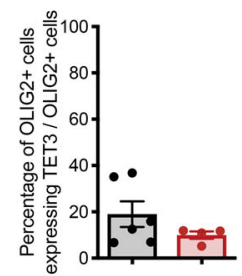

e

OLIG2 / DAPI

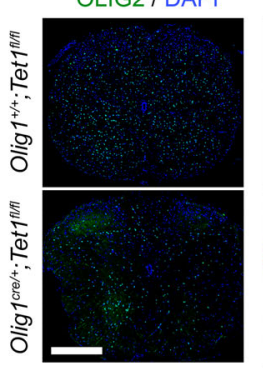

CC1/DAP|
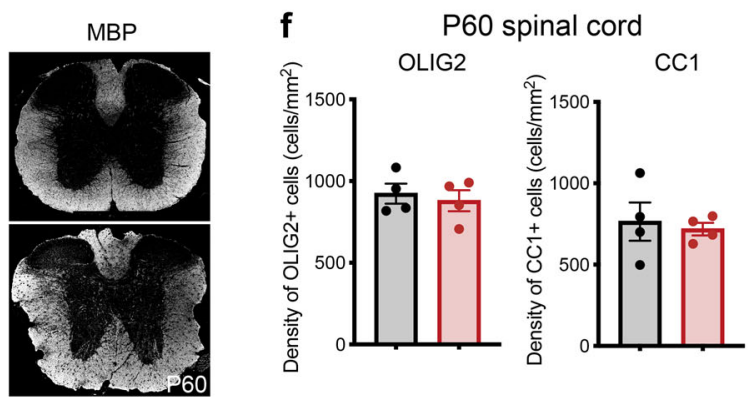

g P60 spinal cord

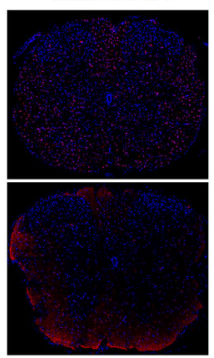

MBP

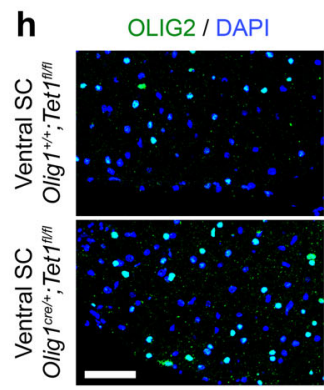

CC1 / DAPI
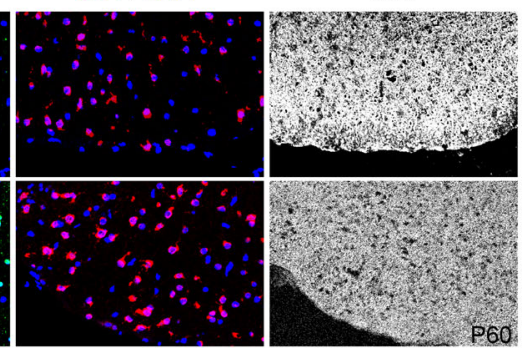

i
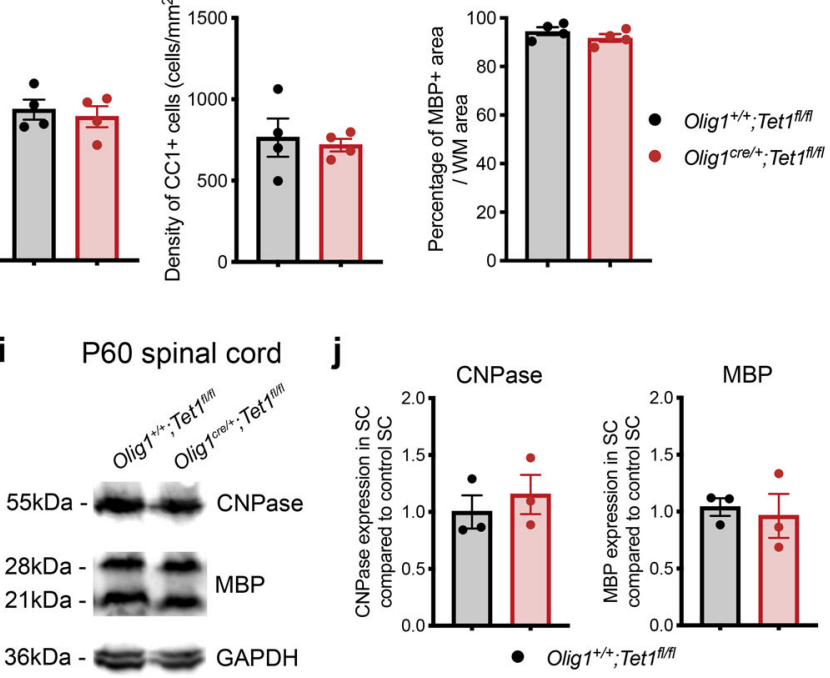

k
Olig1 $^{+/+} ;$Tet $^{\text {Pfit }}$

P60 spinal cord
I Olig ${ }^{\text {creet+ }} ;$ Tet $1^{\text {trot }}$

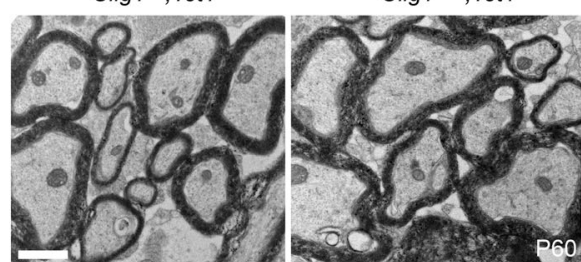

Myelinated axons

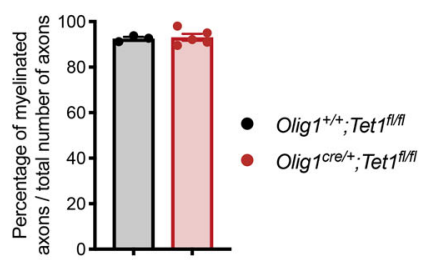

- P60 corpus callosum

MBP
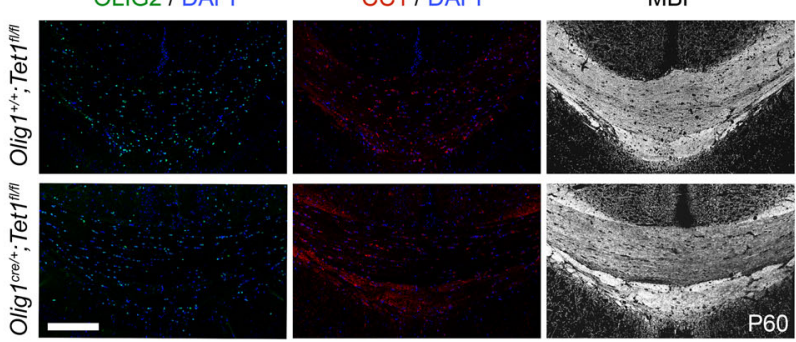

P60
0

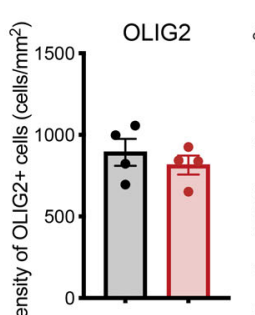

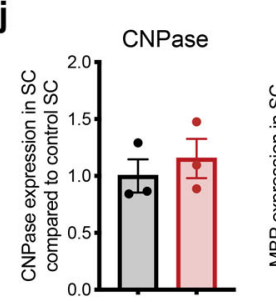

CNPase

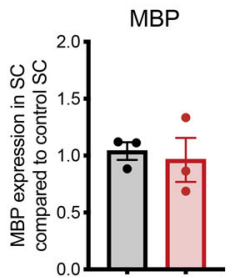

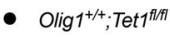

- Olig $1^{\text {crel/t; }}$ Tet $1^{\text {thlt }}$ m

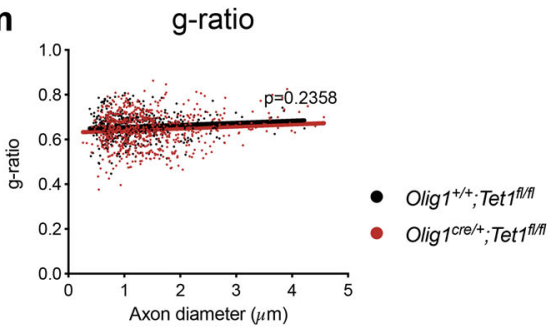

line (Fig. 4n). Adult P60 inducible Tet1 mutants and control mice received one week of tamoxifen induction by gavage prior to LPC-injection in the spinal cord (Fig. 4n). Immunohistochemistry was used to validate specific recombination, and confirm the lower protein levels of TET1 in OLIG2 + cells-but not in any other cell type-in the inducible Tet1 mutants compared to controls (Supplementary Fig. 6d). Lower TET1 expression in
OLIG2 + cells was associated with decreased $5 \mathrm{hmC}$ immunoreactivity at $14 \mathrm{dpl}$ (Fig. 4o), and inefficient remyelination, assessed by Fluoromyelin staining (Fig. 4p) and MBP immunoreactivity in lesioned spinal cords (Supplementary Fig. 6f). Also, in the Tet1 inducible mutants, the inefficient remyelination could not be attributed to decreased numbers of OLIG $2+$ and CC1 + cells as the population size was similar in mice of the two genotypes 


\begin{abstract}
Fig. 3 Ablation of Tet1 during development is compatible with normal myelination in the adult central nervous system. a Photograph of adult controls

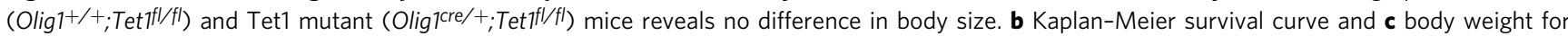
controls $(n=24)$ and Tet1 mutants $(n=13)$. Error bars represent SEM. d Percentage of TET1, TET2, and TET3 expressing OLIG2 cells in the corpus callosum of mice of the two genotypes. Note decreased percentage of OLIG2 + cells expressing TET1 without compensatory increase of TET2 or TET3 expressing cells. Error bars represent SEM for $n=7$ control mice and $n=4$ Tet1 mutants ( ${ }^{\star \star \star} p=0.0010$ for TET1, $p=0.2801$ for TET2, $p=0.2338$ for

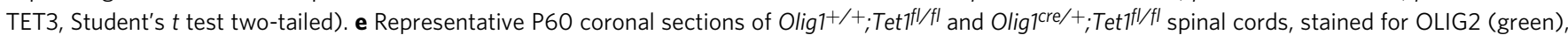
CC1 (red), MBP (white), DAPI (blue). Scale bars $=500 \mu \mathrm{m}$. f Quantification of OLIG2 + and CC1 + cell density (number of cells per mm²) in the spinal cord of mice of the indicated genotypes. Error bars represent SEM for $n=4$ mice ( $p=0.6482$ for OLIG2, $p=0.7252$ for CC1, Student's $t$ test two-tailed). g Average MBP + area relative to total white matter (WM) area in coronal spinal cord sections. Error bars represent SEM for $n=4$ mice $(p=0.2693$, Student's $t$ test two-tailed). h Representative confocal micrograph of adult ventral spinal cord in coronal sections from mice of the indicated genotype, stained for OLIG2 (green), CC1 (red), MBP (white), DAPI (blue). Scale bars $=100 \mu \mathrm{m}$. i Representative Western blot of protein extract from control and Tet1 mutants reveals similar levels of the myelin proteins CNPase, and MBP. GAPDH used as loading control. Molecular weight indicated on the left. j Average levels of the myelin proteins CNPase (left) and MBP (right), relative to GAPDH, quantified in three independent experiments. Error bars represent SEM for $n=3$ spinal cords ( $p=0.5347$ for CNPase, $p=0.7295$ for MBP, Student's $t$ test two-tailed). k Representative ultra-micrograph of adult ventral white matter spinal cords from mice of the indicated genotype revealing no difference in myelination between controls and mutants. Scale bar $=$

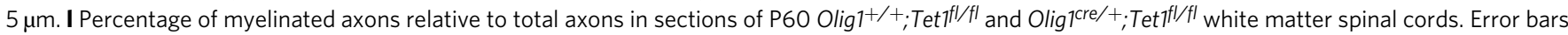
represent SEM for $n=3$ control mice and $n=5$ Tet1 mutants ( $p=0.8009$, Student's $t$ test two-tailed). $\mathbf{m}$ Scatter plot of the g-ratio in myelinated axons of the indicated caliber, in adult control (black) and Tet1 mutant (red) spinal cords. A total of $n=116$ axons in 3 control mice and $n=199$ axons in 5 Tet 1 mutants were quantified (non-linear regression, $p=0.2358$, comparison of slopes with sum-of-squares $F$ Test). $\mathbf{n}$ Representative confocal image of P60 coronal sections from Olig $1^{+/+} ;$Tet $^{f l / f l}$ and Olig 7 cre/ + ; Tet $7^{f l / f l}$ corpus callosum, stained for OLIG2 (green), CC1 (red), MBP (white), DAPI (blue). Scale bar = $500 \mu \mathrm{m}$. O Quantification of OLIG2 + and CC1 + cell density (number of cells per $\mathrm{mm}^{2}$ ) in the corpus callosum of mice of the indicated genotypes. Error bars represent SEM for $n=4$ mice ( $p=0.4644$ for OLIG2, $p=0.7750$ for CC1, Student's $t$ test two-tailed). p Average MBP + area relative to total white matter (WM) area in corpus callosum. Error bars represent SEM for $n=4$ mice $(p=0.9960$, Student's $t$ test two-tailed).
\end{abstract}

(Supplementary Fig. 6e). Collectively, these results suggest that the inability of adult OPCs to reach high levels of DNA hydroxymethylation, as seen in old mice and in the Tet 1 constitutive mutants, did not impair the competence of adult OPCs to either proliferate or start differentiating, although it possibly impaired the expression of other genes regulated by DNA hydroxymethylation and critical for myelin repair.

DNA hydroxymethylation modulates the expression of genes important for myelin repair. To define the identity of the genes regulated by DNA hydroxymethylation during myelin repair in the adult CNS, we adopted a combination of experimental strategies using adult reporter mice ${ }^{43-45}$ and unbiased DNA and RNA sequencing approaches. The Pdgfra-EGFP mice expressing EGFP-tagged histone $\mathrm{H}_{2} \mathrm{~B}^{44}$ were used to sort adult OPCs, following a modified protocol for the removal of meninges and blood vessels (Supplementary Fig. 7a) ${ }^{38}$. This allowed the isolation of a $90 \%$ pure population of progenitors identified by immunoreactivity for PDGFRa and NG2 (Supplementary Fig. 7b) and expression of OPC-specific transcripts (Supplementary Fig. 7c). The Plp-EGFP mice ${ }^{43,45}$ were used to isolate adult OLs, using a similar protocol (Supplementary Fig. 7d). The sorted cell population was characterized by $93 \%$ of cells with MBP and MOG immunoreactivity (Supplementary Fig. 7e) and enrichment for myelin transcripts (Supplementary Fig. 7f).

The genome-wide distribution of the $5 \mathrm{hmC}$ mark was determined by Reduced Representation Hydroxymethylation Profiling (RRHP) of DNA samples from these two characterized populations of sorted adult OPCs and adult OLs. The transcriptional profiles were defined by RNA-sequencing analysis of RNA samples extracted from the same sorted cells (Fig. 5a). RRHP provides an assessment of $5 \mathrm{hmC}$ levels at single base resolution, as the method relies on the glucosylation of $5 \mathrm{hmC}$ by a specific enzyme, which renders that specific cytosine insensitive to digestion by MspI (an enzyme recognizing and digesting the internal cytosine of CCGG sites regardless of methylation) and therefore allows for adapter ligation, amplification, and further sequencing. We verified that an equivalent number of CpGs was present in the DNA samples isolated from aOPC and aOL samples (Supplementary Fig. 8a). We also checked that the hydroxymethylation coverage was similar among distinct biological replicates, although as expected, higher sequencing reads were detected in samples with greater levels of $5 \mathrm{hmC}$ (Supplementary Fig. 8b).

We detected a total of 5583 genes with statistically significant ( $q$-value $<0.05)$ differentially hydroxymethylated regions (DhMR, defined by the presence of at least two concordant CpGs within 2 $\mathrm{kb}$ ) in aOL compared to aOPC. The overwhelming majority of the genes differentially hydroxymethylated during the transition from adult OPC to OL (5511 out of 5583 genes) was characterized by a 40-60\% increase of hydroxymethylation, mostly distributed at promoters and gene regions (Fig. 5b, c). Those hydroxymethylated genes included ontology categories involved in positive regulation of differentiation and cell communication (Fig. 5d). The remaining few genes ( 72 out of 5583 genes), with decreased hydroxymethylation levels, included those involved in negative regulation of cell communication (Fig. 5e). Overall, these data identified hydroxymethylation as an epigenetic mark regulating the expression of genes involved in communication between myelinating cells and neurons. To further define the transcriptional consequences of hydroxymethylation, we analyzed the RNA-sequencing datasets from the same samples of sorted cells (Fig. 5a) and identified transcripts that were either downregulated ( $n=1187$, Fig. 5 f) or upregulated $(n=1739$, Fig. $5 g)$ in adult OLs compared to adult OPCs ( $p$-value $<0.01, q$-value $<0.05)$. Among the downregulated gene ontology categories we identified cell migration, proliferation, communication, and cell adhesion (Fig. 5f), while the upregulated GO categories included cell communication and metabolic processes (Fig. 5g). Among the significantly upregulated transcripts involved in regulation of cell communication, we identified the solute carrier family, such as the anion and cation transporters Slc12a2, Slc22a23, and Slc9a6 (Fig. 5g). By intersecting the transcriptomic datasets with the list of genes differentially hydroxymethylation at promoters (Fig. 5h) and at gene regions (Fig. 5i), we were able to conclude that $91.7 \%$ of the transcripts upregulated in adult OLs compared to adult OPCs were characterized by hydroxymethylation at promoters and $99.0 \%$ at gene regions, with several genes showing DNA hydroxymethylation at both genomic locations. We therefore combined the two lists (1595 genes with increased 
a
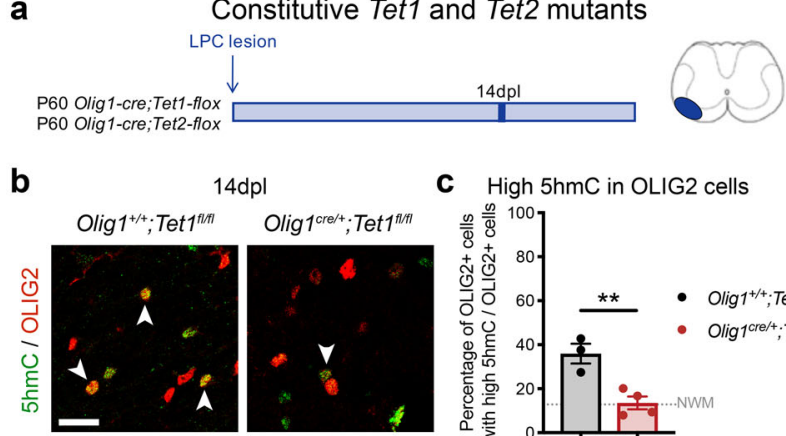

$14 \mathrm{dpl}$

C High $5 \mathrm{hmC}$ in OLIG2 cells
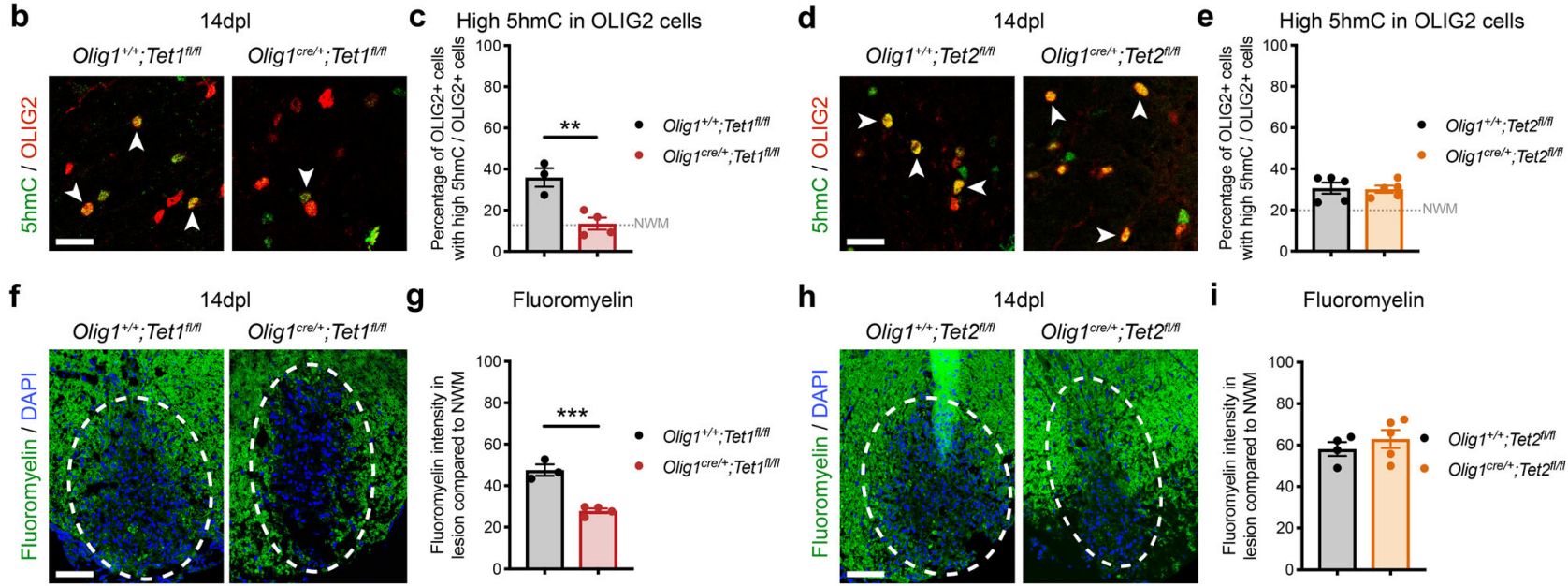

14dpl

g Fluoromyelin

h
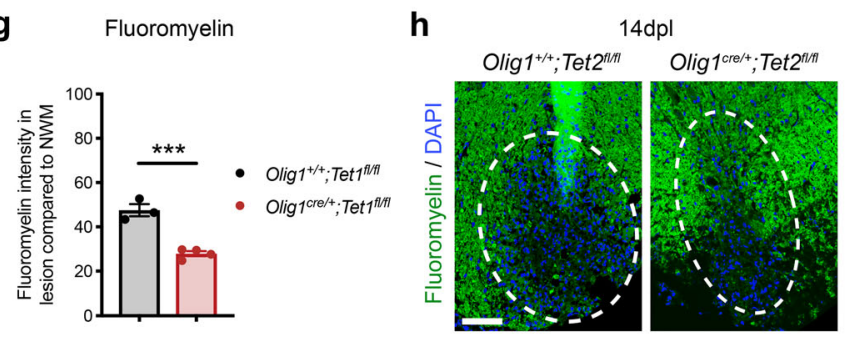

i

Fluoromyelin

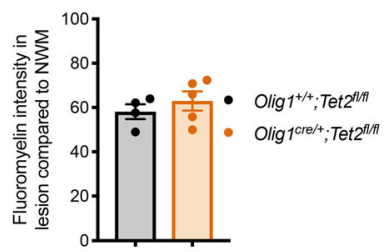

j

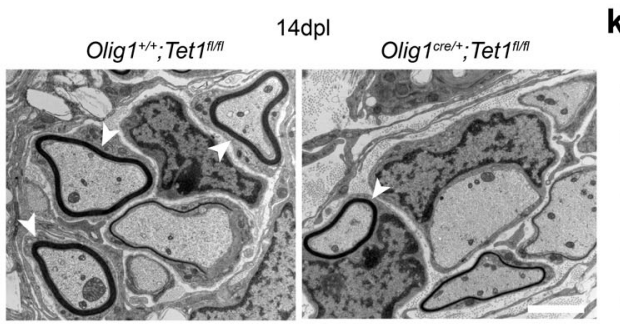

K Remyelinated axons

I

g-ratio

m High $5 \mathrm{hmC}$ in $\mathrm{CC} 1$ cells
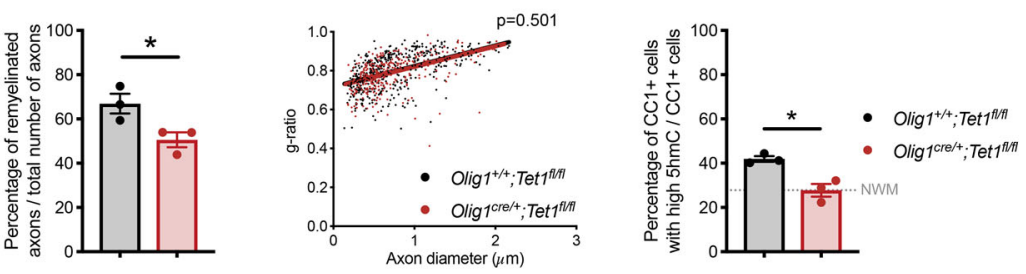

n

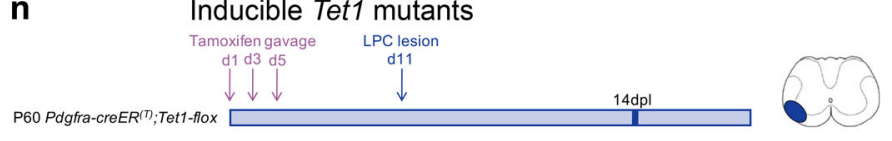

o

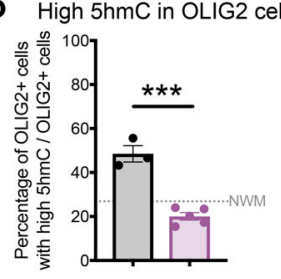

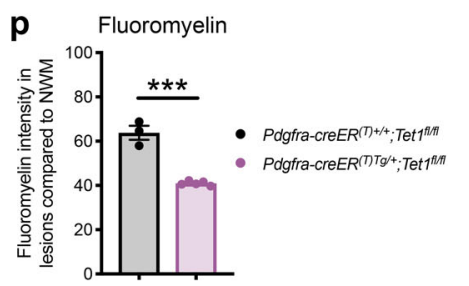

Fig. 4 Constitutive or inducible ablation of Tet1 in OPC mimic the inefficient myelin repair detected in old mice. a Experimental design in constitutive Tet1 or Tet2 knockout mice and controls. b, d Representative confocal image of spinal cord sections stained for $5 \mathrm{hmC}$ (green) and OLIG2 (red) at $14 \mathrm{dpl}$ in Tet1 (b) or Tet2 (d) mutant mice. White arrowheads indicate OLIG $2+$ cells with high levels of $5 \mathrm{hmC}$ immunoreactivity. Scale bar $=50 \mu \mathrm{m}$. c, e Percentage of OLIG2 + cells with high level of $5 \mathrm{hmC}$ in lesioned spinal cord sections at $14 \mathrm{dpl}$ in Tet1 (c) or Tet2 (e) mutants compared to that in wild-type mice. Dotted line indicates relative percentages in unlesioned white matter in the spinal cord (NWM). Average counts quantified in 3-4 sections $/$ mouse for $n=3$ control mice, $n=4$ Tet1 mutants (c) and $n=5$ for control and Tet2 mutants (e). Error bars represent SEM (** $p=0.0070$ for (c), $p=0.8713$ for (e), Student's $t$ test two-tailed). $\mathbf{f}$, h Representative confocal images of spinal cord lesions stained for Fluoromyelin (green) at 14dpl in controls and Tet $1(\mathbf{f})$ or Tet2 (h) mutants (lesion area as white dashed line). Scale bar $=100 \mu \mathrm{m} . \mathbf{g}$, i Fluoromyelin average intensity in control (gray bars) and Tet1 (red bar in $\mathbf{g}$ ) or Tet2 (orange bar in $\mathbf{i}$ ) lesions relative to the levels in unlesioned white matter (NWM) calculated for $n=3$ control mice, $n=4$ Tet1 mutants $(\mathbf{g})$ and $n=5$ for control and Tet2 mutants (i). Error bars represent SEM ( ${ }^{\star \star} p=0.0007$ for $\mathbf{g}, p=0.4304$ for $\mathbf{i}$, Student's $t$ test two-tailed). $\mathbf{j}$ Electron micrographs

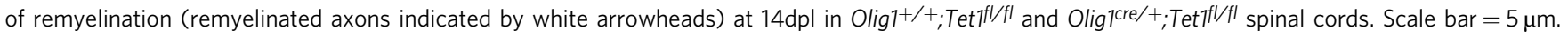
k Percentage of remyelinated axons in controls (gray) and Tet1 mutants (red) at 14dpl, relative to total number of axons. Error bars represent SEM for $n=3$ mice ${ }^{\star} p=0.0433$, Student's $t$ test two-tailed). I Scatter plot of the g-ratio in myelinated axons of the indicated caliber in the lesioned spinal cord of wild-type mice (black) and Tet1 mutants (red) at 14dpl. A total of 107-150 axons were quantified for each mouse and $n=3$ mice for each genotype were assessed (non-linear regression $p=0.501$, comparison of slopes with sum-of-squares F Test). $\mathbf{m}$ Percentage of CC1 + cells with high level of $5 \mathrm{hmC}$ in lesioned spinal cord evaluated at $14 \mathrm{dpl}$ in mice of both genotypes. Dotted line indicates the percentage of CC1 + cells with high level of $5 \mathrm{hmC}$ in unlesioned tracts. Average counts from 3 quantified sections/mouse. Error bars represent SEM for $n=3$ mice ( ${ }^{*} p=0.0109$, Student's $t$ test two-tailed). n Experimental design in inducible P60 Pdgfra-creER $R^{(T)+/+} ; T_{e t} T^{f l / f l}$ and Pdgfra-creER ${ }^{(T) T g /+} ; T e t T^{f l / f l}$ mice, after tamoxifen induction. o Percentage of

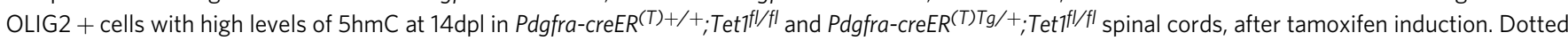
line indicates values in unlesioned tracts. Error bars represent SEM for $n=3$ control mice and $n=5$ inducible Tet1 mutants ( ${ }^{\star \star \star} p=0.0002$, Student's $t$ test two-tailed). p Quantification of Fluoromyelin intensity in lesioned spinal cord at 14dpl, compared to normal white matter (NWM), in Pdgfra-creER $(T)+/+$; Tet $f^{f / / f l}$ and Pdgfra-creER ${ }^{(T) T g /+; T e t} f^{f / / f l}$ after tamoxifen induction. Data represent the average intensity in lesioned compared to unlesioned areas. Error bars represent SEM for $n=3$ control mice and $n=5$ inducible Tet1 mutants ( ${ }^{\star \star \star} p<0.001$, Student's $t$ test two-tailed). 
a

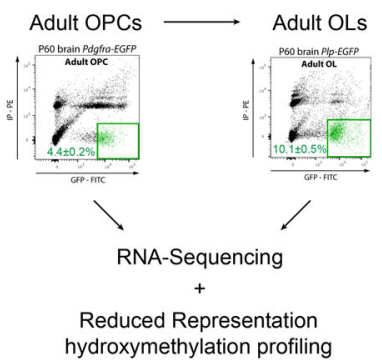

b

Decreased hydroxymethylation in adult OLs compared to adult OPCs

- Increased hydroxymethylation in adult OLs compared to adult OPCs

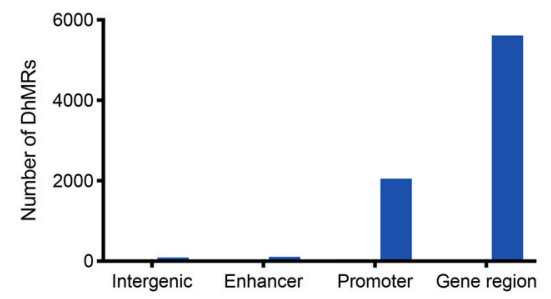

C

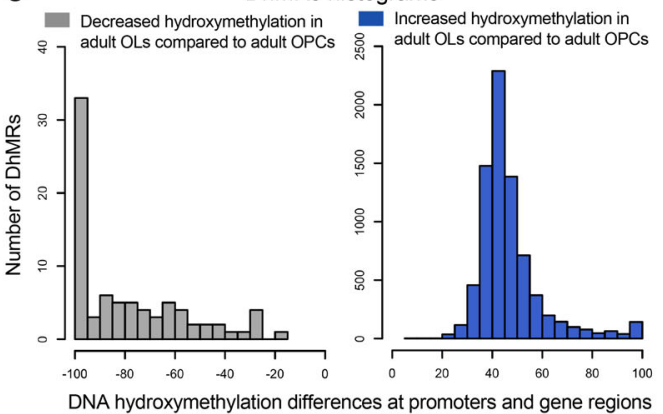

d

5,511 genes with increased hydroxymethylation in adult OLs compared to adult OPCs (DhMRs at promoters and gene regions)

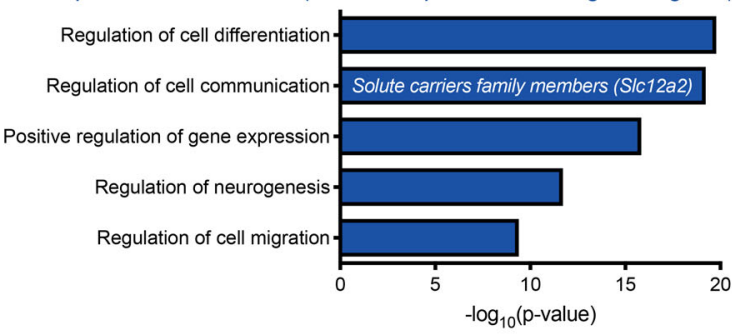

$\mathbf{f}$

1,187 downregulated transcripts in adult OLs compared to adult OPCs Regulation of cell migration of cell proliferation Regulation of cell communication Regulation of inflammatory response Cell adhesion 0

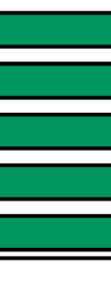

$-\log _{10}(p$-value $)$

h

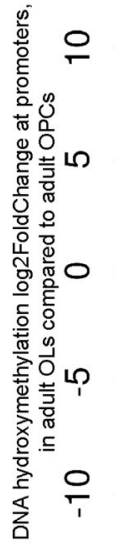

Downregulation

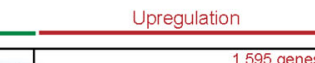

1,004 gen
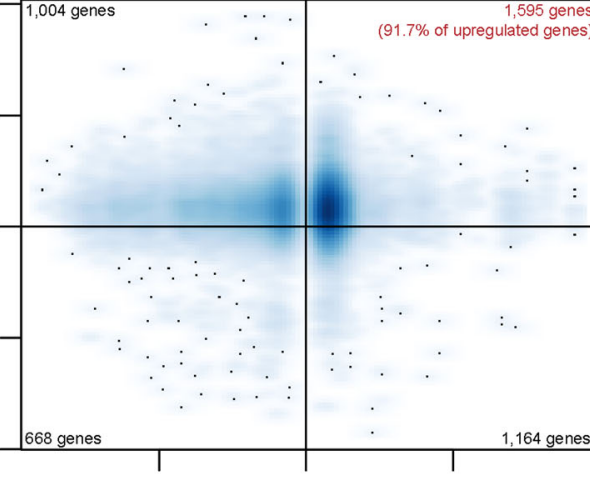

$\because$
$\vdots$
$\vdots$

Gene expression log2FoldChange

in adult OLs compared to adult OPCs

hydroxymethylation at promoter regions and 1721 at gene body regions) to obtain a total of 1726 unique genes with increased expression and increased hydroxymethylation in adult OLs, compared to OPCs. Among those genes we identified the solute carrier gene family (Fig. 5h, i and Supplementary Table 1). As the distribution of hydroxymethylation at gene body regions raised the potential issue of a bias of this DNA modification for larger genes, we conducted a correlation analysis between the number of hydroxymethylated CpGs and gene size (Supplementary Fig. 8c). This analysis revealed that the hyper-hydroxymethylation detected in adult OLs, in particular for the solute carrier gene family, was specific to the stage of differentiation of the cells and not of the

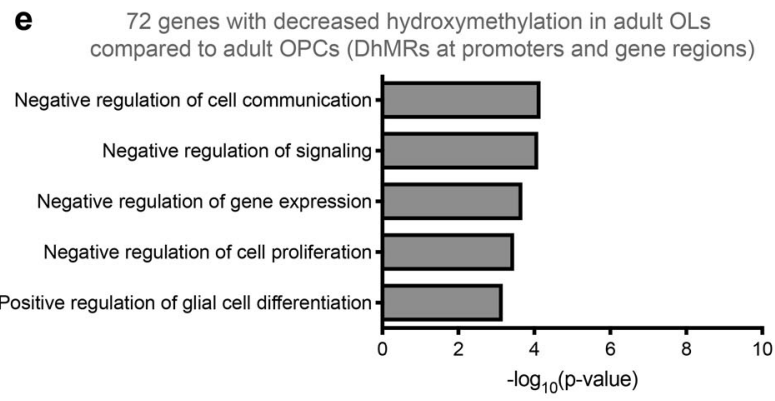

g

1,739 upregulated transcripts in adult OLs compared to adult OPCs
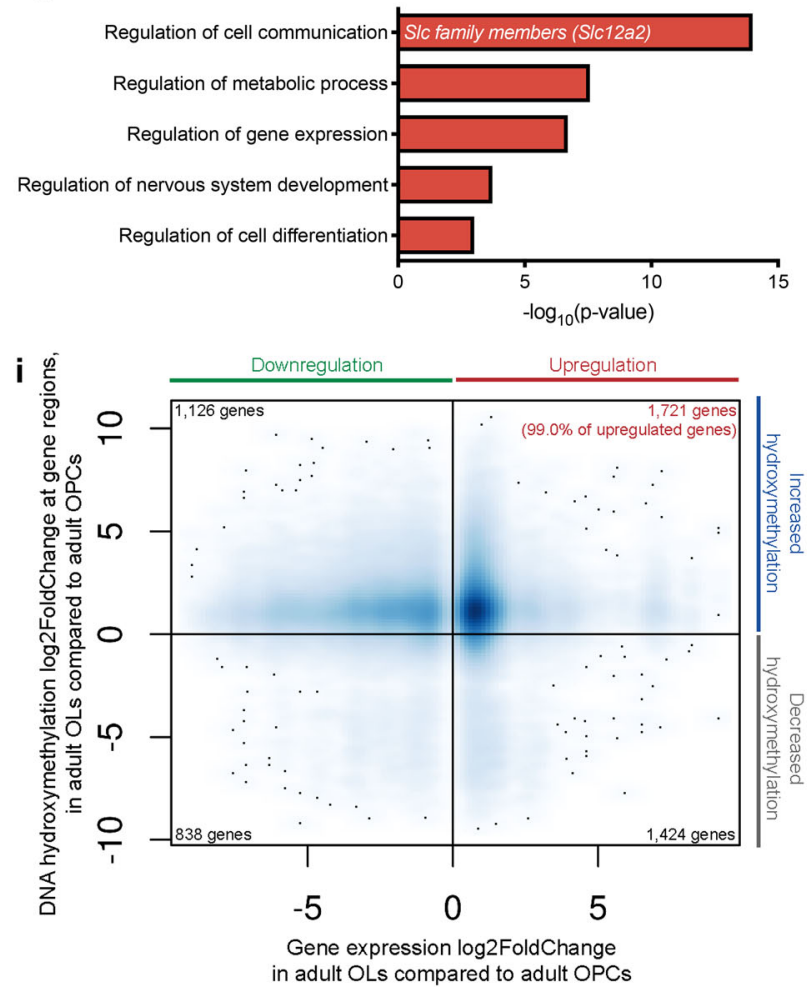

result of large gene size. It is also worth noting that this DNA modification was not uniquely linked to transcriptional activation, as 1142 genes with increased DNA hydroxymethylation (1004 at promoters and 1126 at gene regions) were characterized by lower transcript levels in adult OLs compared to adult OPCs (Fig. 5h, i), suggesting a more global role for DNA hydroxymethylation on gene regulation.

To better understand the relationship between TET1dependent DNA hydroxymethylation and gene expression in adult OLs during the remyelination process, we then compared these lists of unique genes with the differential transcriptomic dataset obtained from preparation of spinal cord samples isolated 
Fig. 5 DNA hydroxymethylation and gene expression in sorted adult oligodendrocyte progenitors and adult oligodendrocytes. a Flow-activated cellsorting of adult OPCs from Pdgfra-H2BEGFP and adult OLs from Plp-EGFP mice followed by RNA and DNA extraction and processing for RNA-Sequencing and RRHP DNA hydroxymethylation analysis. $\mathbf{b}$ Gene features distribution of differentially hydroxymethylated (DhMR) regions in aOLs relative to aOPCs. The bar graphs indicate the number of regions with increased (blue) or decreased (gray) hydroxymethylation at intergenic, enhancer, promoter, and gene regions. c Histograms of the overall distribution of hypo- (gray) and hyper- (blue) hydroxymethylated regions between aOLs and aOPCs samples. The bar graphs identify the number of DhMR at each level of decile DNA hydroxymethylation difference. d Ontology categories of the 5511 genes with increased hydroxymethylation, corresponding to the following GO, in decreasing order (from top to bottom: G0:0030154, G0:0010646, GO:0010628, GO:0050767, GO:0030334 (blue). e Only 72 genes showed decreased hydroxymethylation (gray), in aOLs compared to aOPCs, as defined by the RRHP analysis. f Gene ontology categories of the 1187 transcripts downregulated (green) in aOLs compared to aOPCs. From top to bottom, GO:0030334, GO:0042127, GO:0010646, GO:0050727, GO:0007155. $\mathbf{g}$ Gene ontology categories of the 1739 transcripts upregulated (red) in aOLs compared to aOPCs, as identified by RNA Sequencing analysis. From top to bottom, GO:0050794, GO:0019222, GO:0010468, G0:0051960, GO:0045595. h, i Quadrant plot of the relationship between genes with differential hydroxymethylation at promoters (h) or gene regions (i) and differential transcript (aOLs vs. aOPCs). The $x$ axis indicates log2 fold change of transcript levels. The $y$ axis refers to DNA hydroxymethylation differences. Note the "hot spot" (blue cloud of dots) identifying the abundance of genes with increased hydroxymethylation at promoters and gene regions associated with upregulated transcripts.

four days post-LPC (4dpl) injection of either wild-type control mice $\left(\right.$ Olig $1^{+/+} ;$Tet $\left.1^{f l f l}\right)$ or Tet1 mutants $\left(\right.$ Olig $1^{\text {cre } /+} ;$ Tet $\left.1^{f l / f l}\right)$ (Fig. 6a). Samples isolated from the unlesioned contralateral side of the spinal cords, were used as additional control, in both wild-type mice and Tet1 mutants (Fig. 6a). Consistent with the previously described normal levels of adult myelin, the transcriptome of unlesioned spinal cord samples from mice of the two genotypes, was remarkably similar, with only 7 transcripts being differentially expressed ( $p$ value $<0.01, q$ value $<$ $0.05)$. In contrast, the transcriptome of spinal cord samples isolated during the myelin repair phase, was dramatically different between the two genotypes. Preparations obtained from wild-type mice at $4 \mathrm{dpl}$ were characterized by a substantial reorganization of gene expression during myelin repair, with 2469 upregulated and 1609 downregulated transcripts compared to unlesioned tissue ( $p$ value $<0.01, q$ value $<0.05$ ). Preparations obtained from Tet 1 mutants after lesion, in contrast, were characterized by much smaller changes, with only 121 upregulated and 498 downregulated transcripts ( $p$ value $<0.01, q$ value $<$ $0.05)$, compared to unlesioned tissue. The fact that 2369 (95.9\%) of the 2469 transcripts with increased expression after LPC injection in wild-type spinal were not detected in the Tet 1 mutants, clearly suggested a blunted transcriptional response during myelin repair in the absence of DNA hydroxymethylation (Fig. 6b). Those transcripts included several gene categories related to lipid metabolism (GO:008160), inflammation, autophagy, glial cell activation, cell migration, cellular homeostasis, and response to stress (Fig. 6b). Since hydroxymethylation regulates the expression of genes needed for adult myelin formation, we then asked whether those genes overlapped with the ones regulated by increased hydroxymethylation during the differentiation of adult OPCs into adult OLs (Fig. 5h-i). This analysis detected a statistically significant overlap in 442 genes $(p=$ $2.202774 \mathrm{e}^{-33}$, Fisher test), which we identified as TET1-gene targets, regulated by DNA hydroxymethylation during myelin repair (Fig. 6d). Among them we found several genes encoding for anion and cation transporters, such as those belonging to the solute carrier family. As predicted, a similar analysis for the genes that were downregulated in wild type but not in Tet1 mutants (Fig. 6c) did not reveal a statistically significant overlap $(n=52$ genes, $p=1$, Fisher test) (Fig. 6e). These results define TET1 function as dispensable for developmental myelination, but essential for the activation of a transcriptional program associated with myelin repair after demyelination.

The TET1-target gene SLC12A2 is localized at the axon-myelin interface. As a proof-of-principle, we decided to focus on a TET1-target gene and selected one of the members of the solute carrier gene family regulating anion and cation transport (Fig. 5d, g, Supplementary Table 1). We opted for the sodium/potassium/ chloride symporter SLC12A2 (also known as NKCC1), since it was previously reported to regulate the response of oligodendrocyte lineage cells to GABAergic signals ${ }^{46}$ and to be enriched in newly formed OLs in four distinct transcriptomic datasets ${ }^{47}$, including those from OL directly sorted from the brain ${ }^{48-51}$, and in proteomic datasets from mature oligodendrocytes ${ }^{51}$. The enrichment of this transcript and protein in oligodendroglial cells urged us to further characterize its expression and regulation by TET1.

To verify that Slc12a2 expression was indeed regulated by TET1, we induced the overexpression of the human TET1 catalytic domain (hTET1-CD) in vitro on immunopanned oligodendroglial cultures (Fig. 7a, b). TET1 overexpression was sufficient to induce upregulation of Slc12a2 transcripts in cultured cells (Fig. 7b, c), confirming that Slc12a2 is a TET1-target gene.

SLC12A2 protein expression was first assessed by immunocytochemistry in mixed glial and neuronal cultures, where it was detected at low levels as differentiating OPCs contacted neuronal processes (Fig. 7d). We then assessed SLC12A2 expression in vivo, using immuno-gold electron microscopy of adult optic nerve sections, which unequivocally localized this transporter at the axon-myelin interface, within the first myelin wraps in close proximity to the axon (Fig. 7e). Single-cell rt-qPCR of oligodendrocyte lineage cells sorted from neonatal (P5), young adult (P60), and old (P540) brain, further confirmed that the Slc12a2 transcripts followed the same age-related decline as Tet1 (Fig. 7f). Consistent with SLC12A2 being the product of one of the TET1-target genes, its protein expression also declined in the spinal cord of older mice (Fig. $7 \mathrm{~g}$ ). The time course of SLC12A2 expression during myelin repair in young mice was consistent with the temporal occurrence of DNA hydroxymethylation and the generation of new OL, whereas the inefficient remyelination in older mice was associated with reduced DNA hydroxymethylation and decreased SLC12A2 immunoreactivity (Fig. 7g, h). The localization of SLC12A2 at the axo-myelin interface in young adult mice (Fig. 7e) and the detection of swellings at the axon-myelin interface in older wild type mice (Fig. 7i, j), suggested the importance of TET1-target genes in regulating fluid accumulation at this interface.

Ablation of the TET1-target gene Slc12a2 in zebrafish induces swellings in myelinated axons, reminiscent of those detected in old wild type and young Tet1 mutant mice. As expected from a TET1-target gene, the levels of SLC12A2-as measured by using immuno-gold EM-were reduced in the optic nerve of Tet1 mutants compared to wild type (Fig. 8a, b). We also noted that 


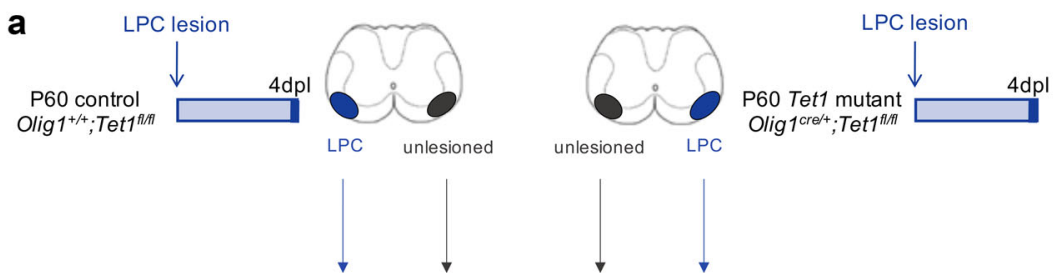

Dissection, chemical dissociation and percoll gradient

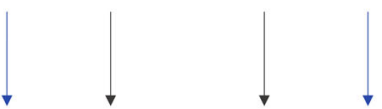

RNA-Sequencing on enriched-oligodendroglial cell population

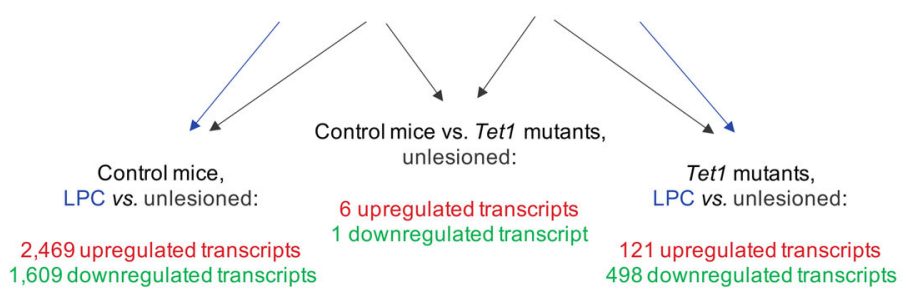

b

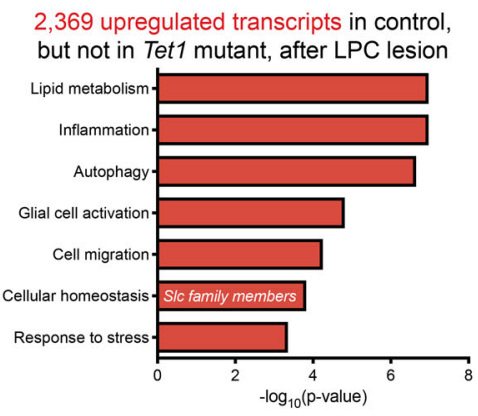

C

1,359 downregulated transcripts in control but not in Tet1 mutant, after LPC lesion
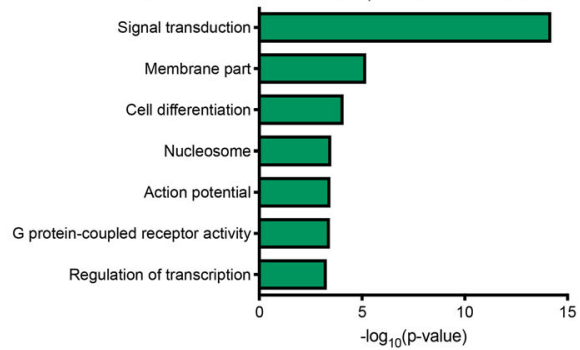

d
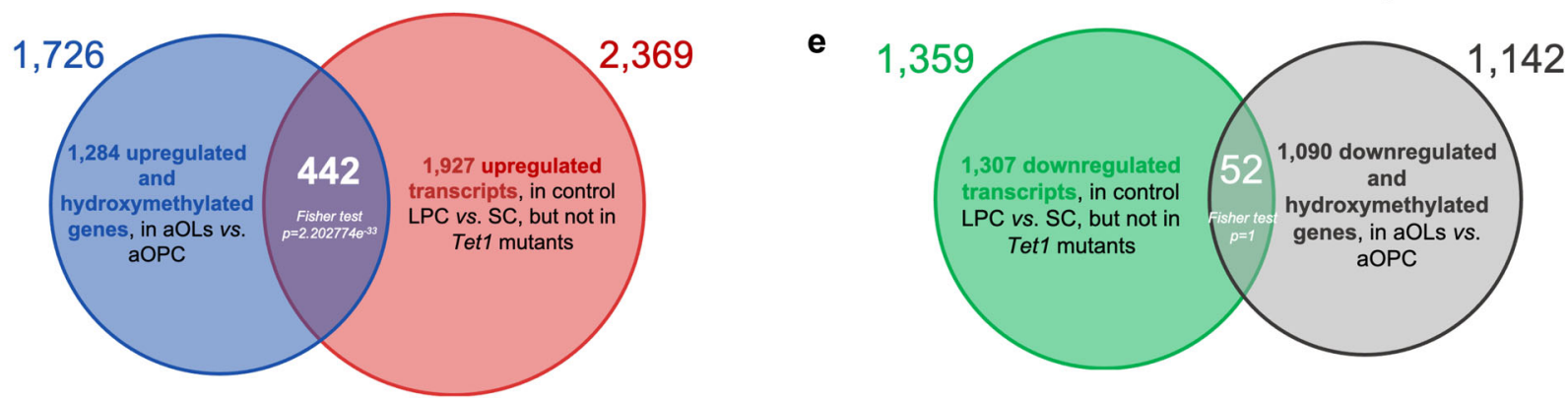

Fig. 6 Identification of TET1-target genes during new myelin formation in adult CNS. a Schematic of the experimental design to identify TET1 target

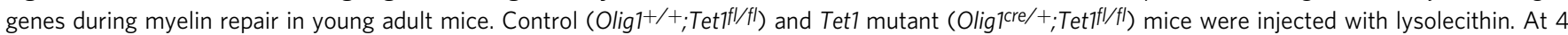
day-post-lesion (4dpl), the demyelinated region and contralateral unlesioned tissue were used for oligodendroglial enriched preparation followed by RNAsequencing. Arrows identify the comparisons that were performed to identify differential gene expression among samples. Myelin repair in control mice was associated with 2469 up- (red) and 1609 down- (green) regulated genes in lesioned tissue compared to unlesioned. In Tet1 mutants, 121 transcripts were up- (red) and 498 down- (green) regulated. Unlesioned tissue of controls and Tet1 mutants showed a total of 7 genes as differentially expressed ( 6 up- and 1 downregulated). b Ontology categories of the 2369 genes that were upregulated during myelin repair only in control spinal cord, but not in Tet 1 mutants. Corresponding GO numbers listed in order from top to bottom: GO:0044242, GO:0032675, G0:0006914, G0:0061900, G0:0030335, GO:0019725, GO:0006950. c Ontology categories of the 1359 genes that were downregulated during myelin repair only in control spinal cords, but not in Tet1 mutants. Corresponding GO numbers listed in order from top to bottom: GO:0007165, GO:0021515, G0:0001508, G0:0003257, GO:0008528,

GO:0044459, GO:0000786. d Venn diagram comparing genes upregulated and with increased hydroxymethylation (at promoters and gene regions) in aOLs vs. aOPCs (blue circle) with genes upregulated in lesioned vs. unlesioned spinal cord in control but not in Tet1 mutants (red). Note the significant overlap ( $p=2.202774 \mathrm{e}^{-33}$, Fisher test two-tailed), of 442 common genes with increased hydroxymethylation and expression levels in newly formed aOLs. e Venn diagram comparing genes downregulated and with increased hydroxymethylation (at promoters and gene regions) in aOLs vs. aOPCs (gray) with genes downregulated in lesioned vs. unlesioned spinal cord in control but not in Tet1 mutants (green). The overlap of 52 genes was not statistically significant ( $p=1$, Fisher test two-tailed).

the increased SLC12A2 immunoreactivity detected in wild type during myelin repair after demyelination, was not detected either in constitutive (Fig. 8c, d) or inducible (Supplementary Fig. 6g) Tet1 mutants. We also showed that the lower levels of Slc12a2 in Tet 1 mutants, were associated with significantly enlarged and swollen space at the axon-myelin interface (Fig. 8e, f), a feature that was reminiscent of the swollen axo-myelinic interface detected in old mice (Fig. 7i, j).

To further define a relationship between swelling at the axon-myelin interface and decreased SLC12A2 levels, we used the zebrafish model system for additional loss-of-function studies. Zebrafish mutants, characterized by a loss of function mutation (ue58) in the gene encoding for a homologue of Slc12a2 $(\operatorname{slc12a2b})$, were identified in an ENU-based forward genetic screen $^{52}$. Myelin formation was first assessed using the stable transgenic reporter $\mathrm{Tg}(\mathrm{mbp}$ :EGFP-CAAX) in slc12a2bue58 mutants and compared it to sibling controls. While myelin formed normally in mutants, we noted the appearance of abnormal fluorescent profiles, indicative of swellings around myelinated axons in the CNS (Fig. 8g). To further characterize this pathology, we carried out time-course analyses of single oligodendrocytes labeled with mbp:mem-Scarlet, which allowed to assess the cellular morphology in better detail (Fig. 8h, i). This analysis showed that although slc12a $2 b^{u e 58}$ mutant and control cells looked similar at early stages of myelin formation (4 daypost fertilization, $4 \mathrm{dpf}$ ) (Fig. $8 \mathrm{~h}$ ), a clear pathology, characterized 

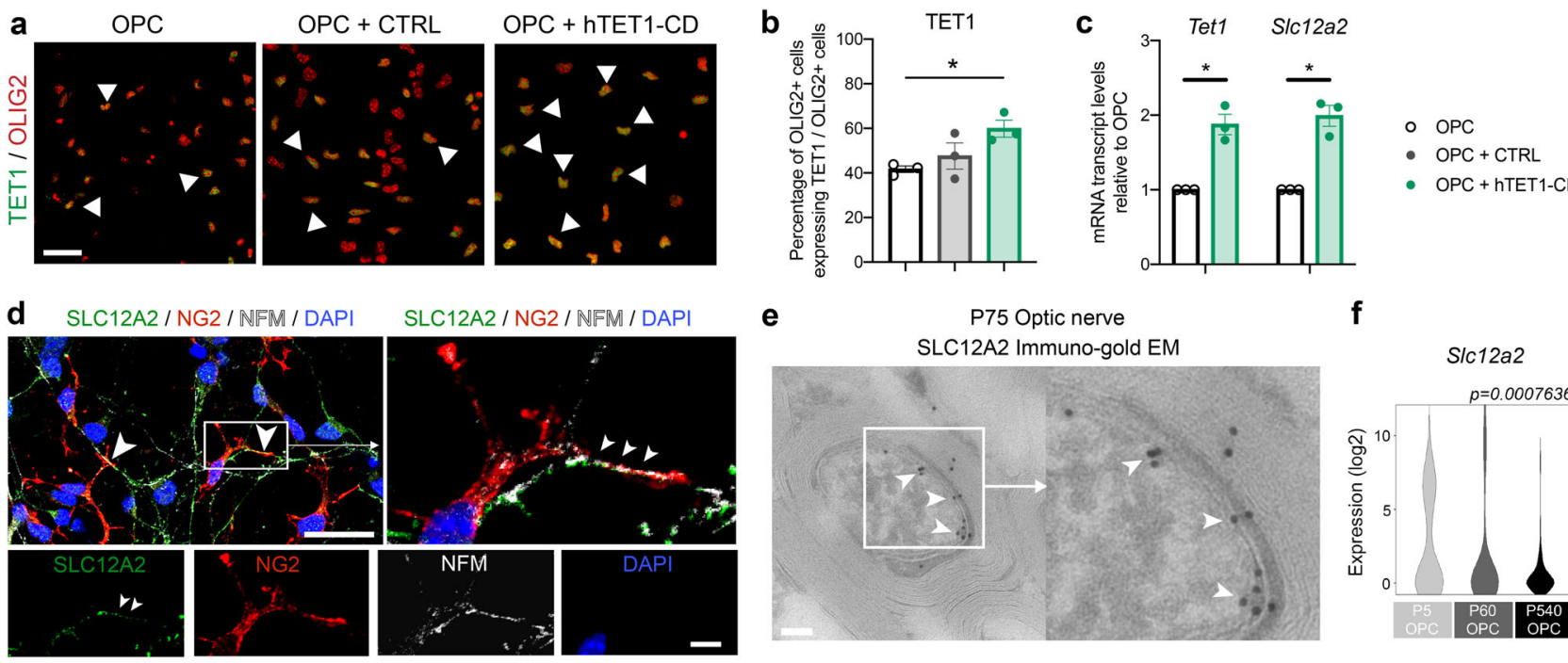

e
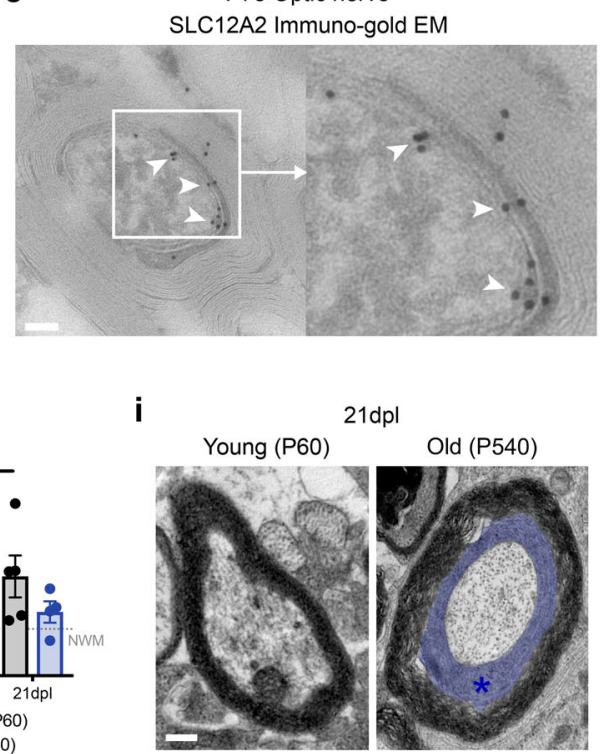

P75 Optic nerve SLC12A2 Immuno-gold EM

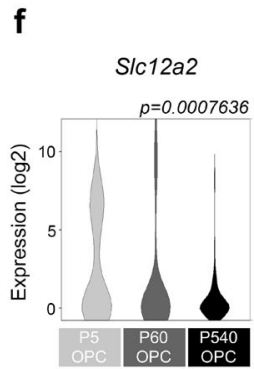

j Swelling at the axon-myelin interface

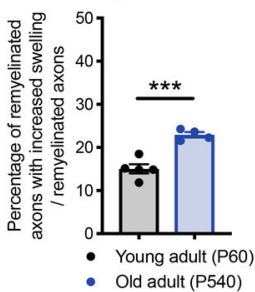

g

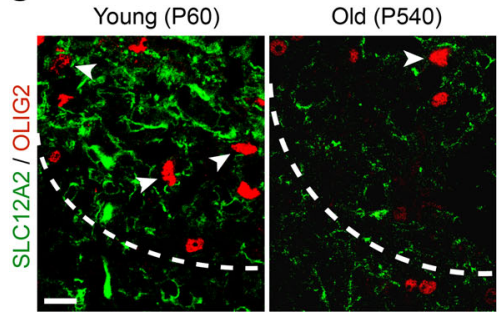

h

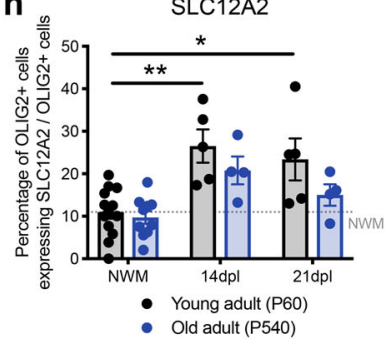

Fig. 7 The protein encoded by the TET1-target gene Slc12a2 is localized at the axon-myelin interface. a Representative images of cultured OPCs, transduced with the indicated lentiviral vectors and then stained for TET1 (green) and OLIG2 (red). White arrowheads indicate co-labeled cells.

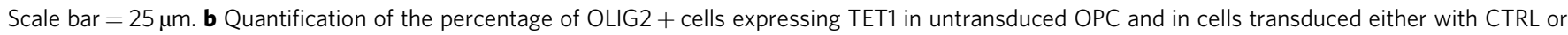
hTET1-CD lentiviral vectors. Error bars represent SEM in $n=3$ independent experiments ( ${ }^{*} p<0.05$, one-way ANOVA). c Quantitative real-time PCR analysis of Tet1 and S/c12a2 transcript levels in immunopanned OPCs after transfection with hTET1-CD lentivirus. Data represent average transcript levels relative to untransfected OPCs in $n=3$ independent experiments. Error bars represent SEM ( ${ }^{\star} p=0.0232$ for Tet1, ${ }^{\star} p=0.0192$ for S/c12a2, Student's $t$ test two-tailed). d Confocal image of mixed neuronal/glial cortical cultures. SLC12A2 (in green) is expressed by differentiating oligodendrocyte progenitors (costained with NG2, in red), and localized at contact points with axons (stained with NFM, in white). DAPI (blue) used as nuclear counterstain. White arrowheads indicate NFM + and NG2 + neuron-glial contact points co-labeled with SLC12A2. Scale bars $=50 \mu \mathrm{m}$ and scale bars $=10 \mu \mathrm{m}$ for high magnification images. e Immunogold staining for SLC12A2 on EM imaging in adult P75 WT optic nerves, showing the localization of SLC12A2 at the axon-myelin interface (white arrow-heads). Scale bar $=5 \mu \mathrm{m}$ and scale bar $=1 \mu \mathrm{m}$ for high magnification images. $\mathbf{f}$ Violin plots of S/c12a2 transcript levels in nOPC at P5 ( $n=61$ single cells), aOPC at P60 ( $n=76$ single cells), and oOPC at P540 ( $n=51$ single cells). Note the age-dependent decline of S/c12a2 transcripts (one-way ANOVA, for age). g Representative confocal image of young and old spinal cord sections, stained 14 days after lesion for SLC12A2 (green) and OLIG2 (red). The dotted white line indicates the lesion border. White arrowheads indicate co-labeled cells. Scale bar $=50$ 4 m. $\mathbf{h}$ Quantification of in the percentage of OLIG2 + cells expressing also SLC12A2 in young and old lesioned spinal cords at 14dpl and 21dpl. Dotted gray line across indicates the percentage of OLIG2 + cells expressing SLC12A2 in unlesioned white matter tracts (NWM). Data represent average values quantified in 4 sections/ mouse for $n=5$ young and $n=4$ old mice ( ${ }^{\star} p<0.05$ and ${ }^{\star \star} p<0.01$, two-way ANOVA, for age and time after lesion). i Representative electron micrographs of young and old spinal cord sections at $21 \mathrm{dpl}$, revealing increased swelling at the axo-myelinic interface (blue area and * asterisk). Scale bar $=10 \mu \mathrm{m}$. $\mathbf{j}$ Quantification of the percentage of remyelinated axons with swelling at the neuro-glial interface in young and old spinal cord lesions at $14 \mathrm{dpl}$. Data represent the average values. Error bars represent SEM for $n=5$ young and $n=4$ old mice ( ${ }^{\star \star \star} p=0.0005$, Student's $t$ test two-tailed).

by the appearance of localized swellings associated with individual myelin sheaths, emerged over time in slc12a2bue58 mutant cells (Fig. 8i). These results provided further evidence in support of the role of solute carriers in the regulation of the axon-myelin interface.

Taken together, our data support DNA hydroxymethylation as an epigenetic modification critical for proper myelin repair in the CNS of young adult mice, which declines with aging. TET1 is identified as the specific enzyme responsible for this process, as lower TET1 levels, detected with aging or after genetic ablation, result in lower expression of its target genes and impaired myelin repair. Importantly, TET1 function is not essential for the "default" myelination program, as white matter tracts in the adult central nervous system of mutants and wild-type mice are virtually indistinguishable. In contrast, TET1 function regulated the expression of several genes involved in myelin repair, including the expression of solute carriers, which regulate ion transport at the axon-myelin interface. Thus, the age-dependent decline of TET1 in mice, results in an overall decreased transcriptional program, which prevents efficient repair of demyelinated lesions.

\section{Discussion}

Myelin formation is a well-studied process in the developing central nervous system. Neonatal OPCs globally reorganize their transcriptome to repress genes involved in the regulation of proliferation and migration, as well as transcriptional inhibitors of myelin genes ${ }^{5,6}$. We and others reported on the importance of this developmental process and identified several epigenomic 


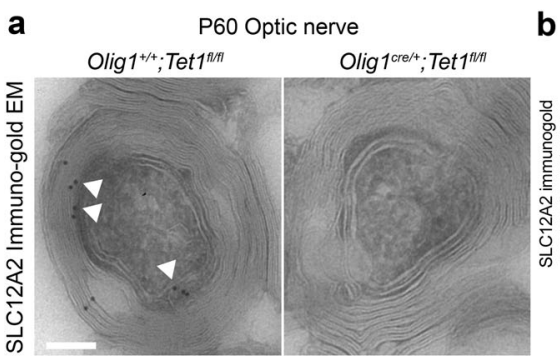

e

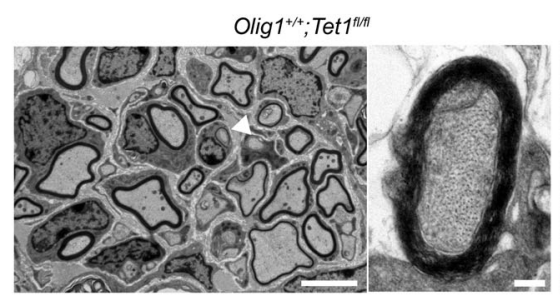

b

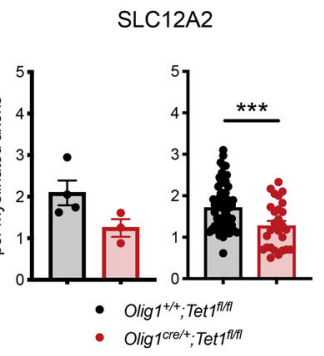

$14 \mathrm{dpl}$
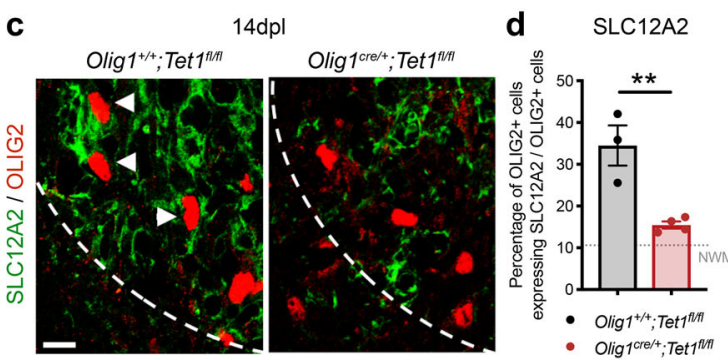

f Swelling at the axon-myelin interface
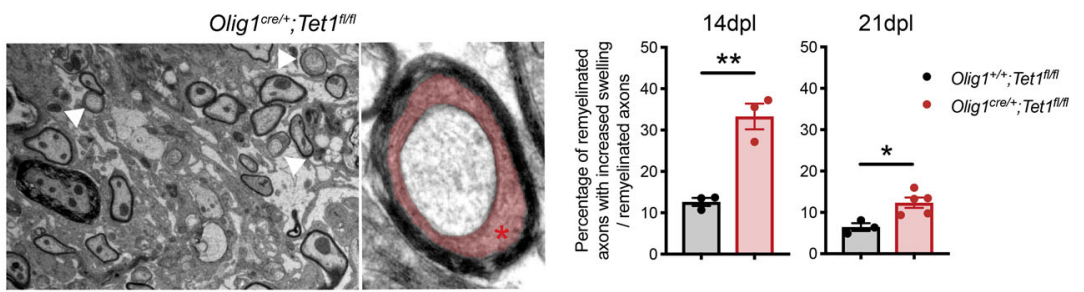

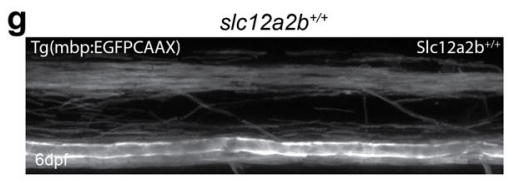

$\operatorname{slc} 12 a 2 b^{u e} 58$

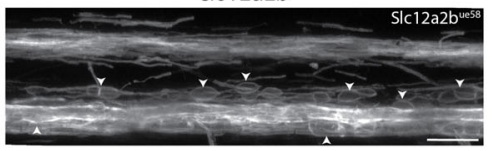

h

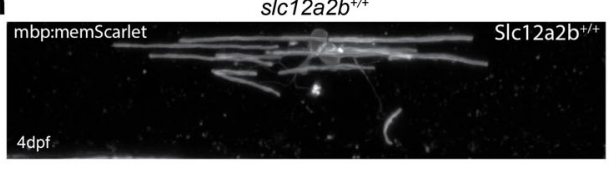

slc12a2bue 58

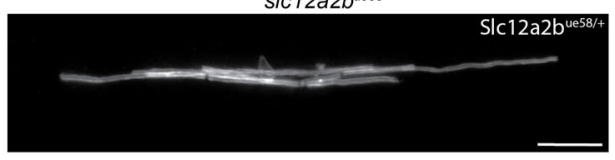

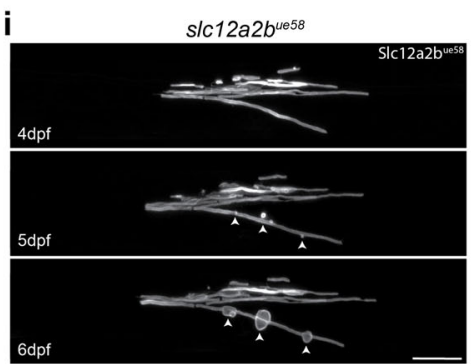

Fig. 8 Ablation of SIc12a2b in zebrafish induces myelin swellings reminiscent of those detected in old mice. a Ultra-micrograph of immunogold staining

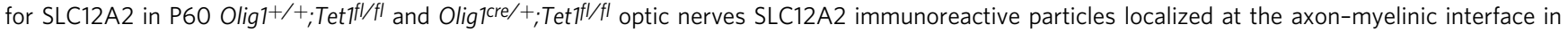
control tissue(white arrowheads). Scale bar $=5 \mu \mathrm{m}$. $\mathbf{b}$ Quantification of the SLC12A2 particles in optic nerves. Data represent of the average number of SLC12A2 gold particles per mouse (left) and per axon (right). Error bars represent SEM for myelinated axons, quantified in $n=4$ control and $n=3$ mutant mice (total of at least 27 and at maximum 64 myelinated axons quantified in one replicate) $\left(p=0.0866,{ }^{\star \star \star} p=0.0008\right.$, Student's $t$ test two-tailed). c Representative confocal image of spinal cord at 14dpl stained for SLC12A2 (green) andOLIG2 + (red), in mice of the indicated genotype. White arrowheads indicate co-labeled cells. Scale bar $=50 \mu \mathrm{m}$. d Percentage of OLIG2 + cells expressing SLC12A2 in lesioned spinal cords in mice of the two genotypes, at the $14 \mathrm{dpl}$ time point. Dotted line refers to the percentage of OLIG2 + cells expressing SLC12A2 in unlesioned tracts. Error bars represent SEM for $n=3$ control mice and $n=4$ Tet1 mutants ( ${ }^{\star \star} p=0.0059$, Student's $t$ test two-tailed). e Representative electron micrographs of spinal cord sections

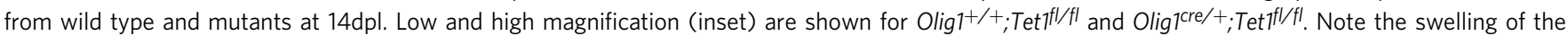
axomyelinic space in Tet1 mutants (red area and asterisk). Scale bar $=10 \mu \mathrm{m}$. $\mathbf{f}$ Quantification of the percentage of remyelinated axons with increased swelling in Olig ${ }^{+/+} ;$Tet $^{f l / f l}$ and Olig $1^{\text {cre } /+} ;$ Tet $^{f l / f l}$ lesions at $14 \mathrm{dpl}$ and $21 \mathrm{dpl}$. Data are average counts. Error bars represent SEM for $n=3$ control mice and Tet1 mutants at $14 \mathrm{dpl}, n=3$ control mice and $n=5$ Tet1 mutants at $21 \mathrm{dpl}$ ( ${ }^{\star *} p=0.0032$ at $14 \mathrm{dpl},{ }^{*} p=0.0164$ at $21 \mathrm{dpl}$, Student's $t$ test two-tailed). $\mathbf{g}$ Lateral views of the spinal cord in $6 \mathrm{dpf} \operatorname{Tg}(\mathrm{mbp}$ :EGFP-CAAX) zebrafish where myelinating glia in the CNS are labeled. Compared to wild-type sibling controls (left panel), larvae homozygous for the slc12a2bue58 mutation (right panel) show disrupted myelin morphology (white arrowheads). Scale bars $=20 \mu \mathrm{m}$. $\mathbf{h}$ Single mbp:mem Scarlet-expressing oligodendrocytes in wild-type (left panel) and slc12a2bue58 heterozygote siblings (right panel) at $4 \mathrm{dpf}$. Scale bars $=20 \mu \mathrm{m}$. i Example time course showing the development of the myelin phenotype in single mbp:mem Scarlet-expressing oligodendrocytes in s/c12a2bue58 homozygous mutants from 4 to $6 \mathrm{dpf}$. White arrowheads point to localized areas of myelin disruption. Scale bar $=20 \mu \mathrm{m}$.

regulators responsible for this transition, including histone deacetylases ${ }^{9,18,53}$, repressive histone methyltransferases 8,54 , and DNA methyltransferases ${ }^{16}$, which repress gene expression and favor a model of nOPC differentiation due to de-repression of myelin gene expression.

In the adult CNS, aOPCs retain the ability to form new myelin in response to damage or loss, a process that becomes less efficient with aging $1,17,18$. Several groups have attempted to understand the underlying causes for this age-dependent decline in myelin repair. External factors, such as declining growth factor concentrations or changes in stiffness of the extracellular matrix, for instance, have been suggested as potential culprits for the agedependent decline in remyelination ${ }^{1,2,33-37}$. However, it has been long recognized that nOPC and aOPC are also characterized by a different ability to proliferate, migrate, and differentiate ${ }^{38,55-61}$.
For example, aOPCs show decreased responsiveness to the same concentration of growth factors and cytokines compared to nOPCs $^{62}$. From a molecular standpoint, these results support intrinsic differences in the properties of nOPC and aOPC, a concept which is supported by the transcriptional heterogeneity of OPCs at different ages $2,49,51$. Despite the large number of studies supporting age-dependent differences in OPC, there is still relatively little information regarding the epigenetic landscape of aOPC, especially during the age-dependent decline observed in myelin repair.

As DNA methylation is the single most significant epigenetic mark predictive of biological age ${ }^{20}$, and yet ablation of the DNMTs in oligodendroglial cells only modestly impacted myelin repair ${ }^{19}$, we focused this study on DNA hydroxymethylation, catalyzed by the TET enzymes. These enzymes are methyl- 
cytosine dioxygenases, which hydroxylate methylated cytosine residues $(5 \mathrm{mC})$ into hydroxylated forms $(5 \mathrm{hmC})$ that can be then converted into formyl-cytosine and carboxyl-cytosine. These marks can eventually be excised from the $\mathrm{DNA}^{22}$, thereby removing the DNA methylation-dependent repression of genes and favoring gene expression $21,22,24-27$. We previously reported that DNA methylation, mediated by DNMT1 is necessary for the transcriptional repression of several inhibitors during the differentiation of nOPCs in the developing brain ${ }^{16}$. Here, we show that higher levels of both DNA methylation and hydroxymethylation are detected in aOLs compared to aOPCs.

The overall genome-wide distribution of hydroxymethylation in aOLs identified in our study, is consistent with previous reports $^{63-65}$, as it is primarily localized at promoters and gene body regions. The high levels of hydroxymethylation at gene body is not correlated with greater expression of larger genes in aOLs. It is interesting to note that increased hydroxymethylation in aOLs is correlated with gene up- and downregulation, suggesting a global role of DNA modifications in gene expression, which could be explained by different genomic location and/or abundance at specific loci. Increased hydroxymethylation is detected at genes regulating cell-cell communication and lipid metabolism, rather than myelin genes, a finding which is consistent with the lack of a developmental myelin phenotype in Tet 1 mutants. Together, these data support the unique functional importance of DNA hydroxymethylation in newly formed OLs, to coordinate the transcriptional activation of genes regulating lipid metabolism and genes regulating ion homeostasis at the axon-myelin interface. As such, successful myelin repair in the spinal cord of young mice is preceded by increased levels of hydroxymethylation as aOPCs transition into newly formed OLs, which express genes involved in lipid metabolism and ion exchange at the axon-myelin interface. In contrast, age-dependent decline of hydroxymethylation results in inappropriate levels of gene expression in old mice and inefficient myelin repair, characterized by the presence of aberrant swellings at the axon-myelin interface.

Our data also identify TET1 as the main enzyme catalyzing DNA hydroxymethylation in oligodendroglial lineage cells in the young adult spinal cord and whose levels decline with age. TET2 is also expressed in aOPCs, but its levels remain constant over time. TET3, although previously reported in neonatal cultures of cortical oligodendrocyte lineage cells ${ }^{28}$, is not detectable in OPCs or OLs in the adult spinal cord. Reduced TET1 levels in older mice are associated with reduced hydroxymethylation in oligodendroglial cells, a finding detected also in young adult mice with oligodendrocyte lineage-specific ablation of Tet1, but not of Tet2. This underscores the importance of TET1 as the main enzyme responsible for the deposition of the $5 \mathrm{hmC}$ epigenetic mark in aOPCs as they differentiate into aOL, and raises the question on functional differences between the TET1 and TET2 isoforms. A potential explanation for the isoform specific role of TET1 in aOPCs, could be presence of a "CXXC" domain, which enables the protein to directly bind DNA and is not present in TET2 24,66 . It is also conceivable that TET1 and TET2 may bind to distinct protein partners in the nuclei of newly formed aOLs and in turn activate TET1 and inhibit TET2 enzymatic activity ${ }^{67}$, a question that deserves future investigation.

The higher levels of hydroxymethylation detected in aOPCs compared to nOPCs, are consistent with the concept that distinct epigenetic marks regulate myelin formation in the developing and adult CNS. Developmental myelination is characterized by the establishment of a repressive epigenomic landscape as nOPCs differentiate into nOLs. As such, it is not surprising that neither Tet1 nor Tet 2 mutants show defective developmental myelination. However, it is important for aOPCs to activate transcription using TET1-dependent hydroxymethylation as cells transition from a progenitor stage to newly formed aOLs. This modification does not impact the process of differentiation from aOPCs to aOLs, but rather impacts the expression of genes that regulate the stability of the myelin sheath, including genes regulating lipid metabolism and regulate ion homeostasis and cell communication. Among the most significant hydroxymethylated genes whose transcripts are also upregulated during myelin repair, we identify the family of solute carriers, which includes the Slc12a2 gene. The protein encoded by this gene-also known as $\mathrm{NKCC} 1-$ is a sodium/potassium/chloride transporter, previously reported to be expressed in neuronal ${ }^{68,69}$ and glial cells ${ }^{46,68,69}$. Since SLC12A2/NKCC1 regulates the overall intracellular chloride concentration in neurons and in nOPCs, it has been reported to impact the response of OPC to GABAergic inputs ${ }^{46,69}$. At the same time, due to its regulation of cation concentration, this molecule is of particular importance in regulating also calcium influx, especially in pathological conditions affecting the developing brain, such as hypoxia/ischemia ${ }^{70,71}$. Besides its role as ion co-transporter, SLC12A2/NKCC1 is also highly expressed in epithelial cells, where it is strongly polarized and confined to the basolateral membrane ${ }^{70,71}$. Oligodendrocytes are also highly polarized cells and recent transcriptomic and proteomic studies support the highest levels of SLC12A2 in newly formed myelinating oligodendrocytes ${ }^{47-51}$. Our results confirm these most recent findings, as we detect high levels of SLC12A2 at the axon-myelin interface during myelin repair in young, but not in old mice. As SLC12A2 has been shown to regulate cell volume in epithelial cells ${ }^{72,73}$ and promote cell shrinkage in the mammalian brain $^{74,75}$, we hypothesize that its localization within the first myelin wraps close to the axon, is indicative of a regulatory role of the volume of the axo-myelinic space. Consistent with this hypothesis, we detect swelling of this space in the CNS of zebrafish mutants for slc12a2b, a finding which was also detected in peripheral axons ${ }^{52}$. It is worth noting that this phenotype is distinct from the one previously reported for the slc12a2a mutant, which was described to have small ears, due to the loss of endolymph, but no myelin phenotype either in the PNS or in the $\mathrm{CNS}^{76}$. Overall, these data suggest that $s l c 12 a 2 b$ can compensate for the slc12a2 loss, while slc12a2 is not sufficient to compensate the $s l c 12 a 2 b$ zebrafish mutation. The potential impact of the axomyelinic swelling detected in mice and zebrafish with decreased expression of TET1 or its gene target Slc12a2, has been highlighted by a recent report that changes in the space surrounding the axon, may decrease the speed of axial conduction of the action potential ${ }^{77}$. Collectively, these findings suggest that the agedependent decline of TET1, by altering the axo-myelinic junction, may further slowdown axonal conductance. Thus, despite the morphological evidence of remyelinated axons with the expected g-ratio, the newly generated myelin in older mice may not be functionally able to support effective conduction of action potentials, due to ionic and fluid imbalances at the axoglial junction, a concept which deserves future investigation.

Besides genes regulating ion homeostasis at the axo-glial junction, TET1-dependent hydroxymethylation regulates the expression of genes involved in metabolic processes, but not myelin genes. Accordingly, young adult Tet1 mutants display normal myelin content and structure but myelin repair after a demyelinating injury is defective, possibly due to a combination of metabolic alterations and swellings of the axon-myelin interface. By regulating the levels of solute carriers and metabolic genes, DNA hydroxymethylation, mediated by TET1 in young adults guarantees a functional axon-myelinic interface and successful repair. As animals age, however, the declining levels of TET1 result in inefficient DNA hydroxymethylation during the phase of repair after demyelination. The decreased levels of TET1 gene targets, involved in the regulation of metabolites and ionic 
exchanges create a dysfunctional axon-myelin interface, and further create functional impairments of the repair process.

Our study defines the major role of TET1-mediated DNA hydroxymethylation, as a regulator of gene expression during myelin repair, which becomes defective with aging. Worth noting, in this respect is the dramatic downregulation of the TET enzymes detected in post-mortem brain tissue from multiple sclerosis patients, thereby highlighting the overall translational potential of our findings ${ }^{78}$.

\section{Methods}

Mouse models. All experiments were performed according to approved protocols by the Institutional Animal Care and Use Committee (IACUC) of the Advanced Science Research Center (ASRC), City University of New York (CUNY). Mice were maintained in a temperature $\left(65-75^{\circ} \mathrm{F}\right)$ and humidity $(40-60 \%)$ controlled facility on a 12-h light-dark cycle with food and water ad libitum. Mice from either sex were used and mutants were checked for survival and weight every day from birth to weaning. We used distinct reporter mouse lines for flow-activated cell-sorting: Pdgfra-H2BEGFP to sort oligodendrocyte progenitor cells ${ }^{44}$ (RRID:

IMSR_JAX:007669) and a previously characterized Plp-EGFP mouse to sort oligodendrocytes ${ }^{43,45}$. For conditional knock-out mouse lines, we crossed and bred the oligodendroglial-specific Olig1-cre ${ }^{39}$ (RRID:IMSR_JAX:011105) line with the Tet1-flox (gift from. Pr. Yong-Hui Jiang) ${ }^{40}$ or with the Tet2-flox ${ }^{41}$ (RRID: IMSR_JAX:017573) lines. The Tet1-flox line was generated by flanking exon 4 with loxP sites ${ }^{40}$, resulting in loss of exon 4 in OLIG1 + cells, and out-of-frame fusion of exons 3 and 5, yielding an unstable truncated product lacking the catalytic domain of TET1 ${ }^{79}$. For conditional inducible deletion, we crossed and bred the oligodendroglial-specific Pdgfra-creER ${ }^{(T)} 42$ (RRID:IMSR_JAX:018280) line with the Tet1-flox line.

Zebrafish husbandry and transgenic lines. Adult zebrafish were housed and maintained in accordance with standard procedures in the Queen's Medical Research Institute zebrafish facility, University of Edinburgh. All experiments were performed in compliance with the UK Home Office, according to its regulations under project licenses 60/8436, 70/8436, and PP5258250. Adult zebrafish were subject to a 14/10 hours, light/dark cycle. Embryos were produced by pairwise matings and raised at $28.5^{\circ} \mathrm{C}$ in $10 \mathrm{mM}$ HEPES-buffered E3 Embryo medium or conditioned aquarium water with methylene blue. Embryos were staged according to days post-fertilization (dpf). For live imaging, the $\mathrm{Tg}(\mathrm{mbp}$ :EGFP-CAAX) transgenic line was used. The ue58 allele was identified during an ENU-based forward genetic screen as discussed in Marshall-Phelps et al. ${ }^{52}$.

Lysolecithin injection. Injections were carried out in the ventrolateral spinal cord white matter of 8-week-old animals of either sex, as previously described ${ }^{80}$. Briefly, anesthesia was induced and maintained by inhalational of a mixture of isoflurane/ oxygen. The vertebral column was fixed with metal bars onto the stereotaxic apparatus. The spinal vertebrae were exposed, tissue overlying the intervertebral space was cleared, and the dura pierced. A pulled glass needle was advanced through the spine, at an angle of $70^{\circ}$, and $1 \mu \mathrm{L}$ of $1 \%$ lysolecithin (Sigma L4129) was slowly injected into the ventrolateral white matter. Mice were sutured and kept in a warm chamber during recovery. Mice were perfused at 4 day-post-lesion (4dpl), $7 \mathrm{dpl}$, $14 \mathrm{dpl}$, or 21dpl. For RNA-sequencing, control and lesioned fresh spinal cord tissue samples were collected at $4 \mathrm{dpl}$. After mechanical dissociation, they were incubated in enzymatic dissociation medium containing papain $(30 \mu \mathrm{g} / \mathrm{ml}$ in DMEM-Gluta$\max$ ) and supplemented with $0.24 \mu \mathrm{g} / \mathrm{ml} \mathrm{L-cystein} \mathrm{and} 40 \mu \mathrm{g} / \mathrm{ml}$ DNase I. Dissociated samples were layered over a pre-formed Percoll density gradient and centrifuged for $15 \mathrm{~min}$, to discard blood vessels, and enrich for oligodendroglial cell populations. Cells were washed twice in PBS 1X (PBS 10X, Invitrogen), then the dry cell pellets were frozen at $-80^{\circ} \mathrm{C}$, and used for RNA extraction.

Tamoxifen injections. 4-Hydroxytamoxifen (Sigma-Aldrich, T56-48) was dissolved at $40 \mathrm{mg} / \mathrm{ml}$ in $10 \%$ ethanol and $90 \%$ corn oil (Sigma-Aldrich, C8267) for $4 \mathrm{~h}$ at $37^{\circ} \mathrm{C}$ with rotation, and $10 \mathrm{mg}$ were administered by gavage to each mouse at days 1, 3, and 5 before lysolecithin injection. Mice were perfused at $14 \mathrm{dpl}$ (day 25 from the first tamoxifen administration).

Cell sorting. Oligodendrocyte progenitor cells were isolated from post-natal day 5 (P5), P60 and P540 from Pdgfra-H2BEGFP brains ${ }^{44}$, oligodendrocytes were sorted from P60 Plp-EGFP brains ${ }^{44}$, using fluorescence-activated cell sorting as described previously ${ }^{38}$. Tissue was dissected in HBSS 1X (HBSS 10X (Invitrogen), $0.01 \mathrm{M}$ HEPES buffer, $0.75 \%$ sodium bicarbonate (Invitrogen), and $1 \%$ penicillin/streptomycin) and mechanically dissociated. After an enzymatic dissociation step using papain $(30 \mu \mathrm{g} / \mathrm{ml}$ in DMEM-Glutamax, with $0.24 \mu \mathrm{g} / \mathrm{ml} \mathrm{L}$-cysteine and $40 \mu \mathrm{g} / \mathrm{ml}$ DNase I), samples were layered over a pre-formed Percoll density gradient and then centrifuged for $15 \mathrm{~min}$. Cells were then collected and stained with propidium iodide (PI) for $2 \mathrm{~min}$ at room temperature (RT). In a second step, GFP-positive and PI- negative cells were sorted by fluorescence-activated cell sorting (FACS; Aria, Becton Dickinson) and collected in pure fetal bovine serum. For RNA/DNA extraction, cells were washed twice in PBS 1X (PBS 10X, Invitrogen), then the dry cell pellets were frozen at $-80^{\circ} \mathrm{C}$. For immunocytochemistry, cells were washed once in PBS 1X (PBS 10X, Invitrogen), then plated and maintained in Bottenstein and Sato medium (without growth or differentiation factors) ${ }^{38}$ for $12 \mathrm{~h}$ before fixation.

Western blot. Mice of either sex were sacrificed at P14 or P60 and spinal cords were immediately processed for protein extraction. Protein lysates $(50 \mu \mathrm{g})$ were separated by sodium dodecyl sulfate-polyacrylamide gel electrophoresis (SDS-PAGE) and transferred onto a PolyVinylidene DiFluoride (PVDF) (Millipore, Billerica, MA, USA) membrane using a buffer containing $25 \mathrm{mM}$ Tris base, $\mathrm{pH} 8.3,192 \mathrm{mM}$ glycine, $20 \%$ (vol/vol) methanol for $1 \mathrm{~h}$ at $100 \mathrm{~V}$ at $4{ }^{\circ} \mathrm{C}$. Membranes were blocked for $1 \mathrm{~h}$ in $10 \%$ Milk/0.1\% Tween/TBS, then incubated overnight at $4{ }^{\circ} \mathrm{C}$ with the primary antibody diluted $1: 1000$ in $5 \% \mathrm{BSA} / 0.02 \%$ sodium azide/0.1\% Tween/TBS. Antibodies used are: mouse anti-CNPase (Sternberger Inc., SMI-91, 1:5,000), mouse anti-MBP (Millipore, SMI-99, 1:5,000), mouse antiGAPDH (Abcam, ab8245, 1:5,000). After rinsing with $0.1 \%$ Tween/TBS, membranes were incubated $2 \mathrm{~h}$ at room temperature with the secondary light-chain specific antibody (goat anti-mouse IgG, Jackson Immunoresearch, 115-035-174, $1: 10,000)$ in $10 \%$ Milk/0.1\% Tween/TBS. After rinsing, membranes were incubated with ECL (Amersham) for $3 \mathrm{~min}$ and then revealed. Quantification was carried out on three biological replicates per genotype, using ImageJ. Protein expressions were normalized to GAPDH expression, then compared to their respective expression levels in control samples. Uncropped gels are shown in Supplementary Fig. 9.

Single-cell C1 capture and biomark. For each age, sorted single-cells were directly captured on a freshly primed C1 integrated fluidic circuit (IFC) plate $(10-17 \mu \mathrm{m}$ diameter cells). Each plate was examined under a fluorescent microscope to identify single-cell and GFP + slots. RNA and cDNA were prepared using the $\mathrm{Cl}$ PreAmp protocol. P5, P60, and P540 single-cell and bulk samples were then harvested and combined on two $96 \times 96$ dynamic arrays IFC for C1 Biomark. The gene expression of 93 transcripts and 3 controls were analyzed on each of the 188 single-cell samples at the ages analyzed (P5: $n=61$, P60: $n=76$, P540: $n=51$ ), 3 bulk samples and 1 negative bulk sample. $\mathrm{C} 1 \mathrm{R}$ package was used to analyze the normalized data and evaluate $\log 2$ Expression, derived from each $\mathrm{Ct}$, using an ANOVA statistical test.

The primers used for the Biomark study are listed in Supplementary Table 2.

DNA and RNA extraction. DNA and RNA from FAC-sorted cells were isolated simultaneously from the same cell pellet using an AllPrep DNA/RNA Micro Kit (Qiagen) with on-column DNase treatment during the RNA isolation. Cortical and spinal cord tissues RNA were isolated from three biological replicates for each age and condition using TRIzol (Invitrogen) extraction and isopropanol precipitation RNA samples were resuspended in water and further purified with RNeasy columns with on-column DNase treatment (Qiagen). RNA purity was assessed by measuring the A260/A280 ratio using a NanoDrop, and RNA quality checked using an Agilent 2100 Bioanalyzer (Agilent Technologies). DNA quality was checked using a NanoDrop and aQubit Fluorometric quantitation (Thermo Fisher).

Quantitative real-time PCR. For qRT-PCR, RNA was reverse-transcribed with qScript cDNA Supermix (Quanta) and performed using PerfeCTa SYBR Green FastMix, ROX (Quanta), at the ASRC Epigenomic Core. After normalization to the geometric mean of house-keeping genes, the average values for each transcript were calculated as based on the values obtained in all the samples included for each condition. A two-tailed Student's test was performed to assess statistical differences between the average values in each group. For overexpression assay, analysis was performed pair-wise for each cell culture replicate. The primers used are listed in Supplementary Table 3.

RNA-sequencing. For sorted cells, approximately $85 \mathrm{ng}$ of total RNA per sample was used for library construction with the Ultra-Low-RNA-seq RNA Sample Prep Kit (Illumina) and sequenced using the Illumina HiSeq 2500 instrument according to the manufacturer's instructions for $100 \mathrm{bp}$ paired end read runs. For oligodendroglial-enriched preparations from unlesioned and lesioned tissue, approximately $10 \mathrm{ng}$ of total RNA per sample was used for library construction, using with the Ultra-Low-RNA-seq RNA Sample Prep Kit (Illumina) and then sequenced by the Illumina HiSeq 4000 instrument according to the manufacturer's instructions for $100 \mathrm{bp}$ paired end read runs. High-quality reads were aligned to the mouse reference genome (mm10), RefSeq exons, splicing junctions, and contamination databases (ribosome and mitochondria sequences) using the BurrowsWheeler Aligner (BWA) algorithm. Raw counts were generated with the Ensembl GRCm38 release 100 , using uniquely aligned reads to exons by the featureCounts tool (subread 2.0.0). The raw read counts were input into DESeq2 v1.28.1 $1^{81}$, for normalizing the signal for each transcript and to ascertain differential gene expression with associated $p$-values. We used a cut-off of $p$-value $<0.01$ and $q$-value $<0.05$ to identified differentially expressed genes. For gene ontology analysis, we used GOrilla ${ }^{82}$, Enrichr $^{83}$, and REVIGO ${ }^{84}$. We calculated the $p$-value 
of the overlapped datasets using Fisher test in R (universe, total number of genes read on our datasets $=15,614$ ). For the RNA-Sequencing from normal adult brains, the overall mapped reads and sample names are listed below. Data deposited in GEO: accession number GSE122446.

\begin{tabular}{lllll} 
Sample ID & Age & Tissue & Cell purification & Mapped read count \\
pdgfra2mn1 & P60 & Brain & Pdgfr $\alpha$-H2BEGFP & $60,867,788$ \\
pdgfra2mn2 & P60 & Brain & Pdgfr $\alpha$-H2BEGFP & $57,999,332$ \\
pdgfra2mn3 & P60 & Brain & Pdgfr $\alpha$-H2BEGFP & $53,633,707$ \\
plp2mn1 & P60 & Brain & Plp-EGFP & $51,987,110$ \\
plp2mn2 & P60 & Brain & Plp-EGFP & $66,149,474$ \\
plp2mn3 & P60 & Brain & Plp-EGFP & $62,479,413$ \\
\hline
\end{tabular}

For the RNA-sequencing data from the spinal cord of wild-type and Tet1 mutants either unlesioned or after LPC injection, the mapped read counts are listed below. Data deposited in GEO: accession number GSE137611.

\begin{tabular}{|c|c|c|c|c|}
\hline Sample ID & Age & Tissue & $\begin{array}{l}\text { Cell } \\
\text { purification }\end{array}$ & $\begin{array}{l}\text { Mapped rea } \\
\text { count }\end{array}$ \\
\hline Tet1Control_SC_1 & $\mathrm{P} 60$ & $\begin{array}{l}\text { Olig1 } 1^{+/+} ; \text {Tet }_{1} f l / f l \text { control } \\
\text { spinal cord }\end{array}$ & $\begin{array}{l}\text { Percoll } \\
\text { gradient }\end{array}$ & $77,725,400$ \\
\hline Tet1Control_SC_2 & $\mathrm{P} 60$ & $\begin{array}{l}\text { Olig } 1^{+/+} ; \text {Tet } 1^{f l / f l} \text { control } \\
\text { spinal cord }\end{array}$ & $\begin{array}{l}\text { Percoll } \\
\text { gradient }\end{array}$ & $62,825,397$ \\
\hline Tet1Control_SC_3 & $\mathrm{P} 60$ & $\begin{array}{l}\text { Olig1 } 1^{+/+} ; \text {Tet } 1^{f l / f l} \text { control } \\
\text { spinal cord }\end{array}$ & $\begin{array}{l}\text { Percoll } \\
\text { gradient }\end{array}$ & $69,992,533$ \\
\hline Tet1Control_LPC_2 & $\mathrm{P} 60$ & $\begin{array}{l}\text { Olig1 } 1^{+/+} ; \text {Tet } 1^{f l f l} 4 \mathrm{dpl} \\
\text { spinal cord }\end{array}$ & $\begin{array}{l}\text { Percoll } \\
\text { gradient }\end{array}$ & $80,712,352$ \\
\hline Tet1Control_LPC_3 & $\mathrm{P} 60$ & $\begin{array}{l}\text { Olig1 }{ }^{+/+} ; \text {Tet } 11^{f l / f l} 4 \mathrm{dpl} \\
\text { spinal cord }\end{array}$ & $\begin{array}{l}\text { Percoll } \\
\text { gradient }\end{array}$ & $82,184,360$ \\
\hline Tet1Control_LPC_4 & P60 & $\begin{array}{l}\text { Olig } 1^{+/+} ; \operatorname{Tet} 1^{f l / f l} 4 \mathrm{dpl} \\
\text { spinal cord }\end{array}$ & $\begin{array}{l}\text { Percoll } \\
\text { gradient }\end{array}$ & $60,822,630$ \\
\hline Tet1cKO_SC_1 & $\mathrm{P} 60$ & $\begin{array}{l}\text { Olig1 }{ }^{\text {cre } /+} ; \text { Tet } 1^{f l / f l} \text { control } \\
\text { spinal cord }\end{array}$ & $\begin{array}{l}\text { Percoll } \\
\text { gradient }\end{array}$ & $66,951,326$ \\
\hline Tet1cKO_SC_3 & $\mathrm{P} 60$ & $\begin{array}{l}\text { Olig1 } 1^{\text {cre } /+} ; \text { Tet } 1^{f l / f l} \text { control } \\
\text { spinal cord }\end{array}$ & $\begin{array}{l}\text { Percoll } \\
\text { gradient }\end{array}$ & $71,967,927$ \\
\hline Tet1cKO_SC & P60 & $\begin{array}{l}\text { Olig1 }{ }^{\text {cre } /+} ; \text { Tet } 11^{\text {fllfl }} \text { control } \\
\text { spinal cord }\end{array}$ & $\begin{array}{l}\text { Percoll } \\
\text { gradient }\end{array}$ & $61,103,989$ \\
\hline Tet1cKO_LPC_1 & $\mathrm{P} 60$ & $\begin{array}{l}\text { Olig1 } 1^{\text {cre } /+} ; \text { Tet } 1^{\text {fl/fl }} 4 \mathrm{dpl} \\
\text { spinal cord }\end{array}$ & $\begin{array}{l}\text { Percoll } \\
\text { gradient }\end{array}$ & $60,348,900$ \\
\hline Tet1cKO_LPC_2 & P60 & $\begin{array}{l}\text { Olig1 }{ }^{\text {cre } /+} ; \text { Tet } 1^{\text {flffl }} 4 \mathrm{dpl} \\
\text { spinal cord }\end{array}$ & $\begin{array}{l}\text { Percoll } \\
\text { gradient }\end{array}$ & $56,857,377$ \\
\hline Tet1cKO_LPC_3 & $\mathrm{P} 60$ & $\begin{array}{l}\text { Olig1 } 1^{\text {cre } /+} ; \text { Tet } 1^{f l / f l} 4 \mathrm{dpl} \\
\text { spinal cord }\end{array}$ & $\begin{array}{l}\text { Percoll } \\
\text { gradient }\end{array}$ & $78,129,031$ \\
\hline
\end{tabular}

\section{Reduced Representation Hydroxymethylation Profiling (RRHP). RRHP}

libraries were prepared from $200 \mathrm{ng}$ input DNA per biological replicate, according to the manufacturer protocol (ZymoResearch, D5440) ${ }^{85,86}$. The raw sequencing reads were aligned to the mouse reference genome $(\mathrm{mm} 10)$. DNA hydroxymethylation levels were calculated as the relative ratio of cytosine reads for each individual $\mathrm{CpG}$ site, for each sample, compared to all the replicates. Determination of differential hydroxymethylation was performed at the single base level, using only CpG dinucleotides. Differentially hydroxymethylated CpGs were selected at a $q$-value $<0.05$. Differentially hydroxymethylated regions (DMR) were defined by $2 \mathrm{~kb}$ genomic regions containing at least 2 concordantly hydroxymethylated $\mathrm{CpGs}$ (in the same direction). Genes with differentially hydroxymethylated CpGs

( $q$-value $<0.05)$ were compared to differentially expressed genes $(p$-value $<0.01$ and $q$-value $<0.05)$ to generate a scatterplot using smoothScatter in R. For the gene region analysis, all the sites that fell within a gene body were linked to that given gene, and a table of pairs of RRHP sites and genes was produced. The same was done for the promoter analysis, but instead of gene bodies, a flanking region of $2 \mathrm{~kb}$ upstream from the gene's transcription start site to $500 \mathrm{bp}$ downstream from the TSS was used as the region for pairing. All the RRHP data from the above samples have been deposited in GEO: accession number GSE122446.

\begin{tabular}{llllll} 
Sample ID & Age & Tissue & Cell purification & RRHP read count & Unique CpGs \\
pdgfra2mn1 & P60 & Brain & Pdgfr $\alpha-E G F P$ & $13,886,881$ & 980,401 \\
pdgfra2mn2 & P60 & Brain & Pdgfr $\alpha-E G F P$ & $16,214,208$ & $1,005,400$ \\
pdgfra2mn3 & P60 & Brain & Pdgfr $\alpha-E G F P$ & $24,034,708$ & $1,111,395$ \\
plp2mn1 & P60 & Brain & Plp-EGFP & $37,707,720$ & $1,295,473$ \\
plp2mn2 & P60 & Brain & Plp-EGFP & $21,883,753$ & $1,103,851$ \\
plp2mn3 & P60 & Brain & Plp-EGFP & $35,946,466$ & $1,270,551$ \\
\hline
\end{tabular}

Mixed neuron-glia myelinating cultures. Forebrains were removed from 15-day mouse fetuses, dissociated first mechanically and then enzymatically with $0.05 \%$ Trypsin in HBSS $1 \mathrm{X}$ for $15 \mathrm{mn}$ at $37^{\circ} \mathrm{C}$. Cells were washed and filtered gently through nylon mesh ( $63 \mu \mathrm{m}$ pores). The pellet was suspended in DMEM/10\% FBS. Cells were plated on poly-L-Lysine coated glass coverslip. The culture medium consisted of Bottenstein and Sato medium supplemented with 1\% FBS, 1\%penicillin/streptomycin solution, PDGF-AA $(10 \mathrm{ng} / \mathrm{ml})$, with addition of T3 hormone $(45 \mathrm{nM})$ after the third day in culture, to induce differentiation.

Primary oligodendrocyte progenitor cultures and overexpression studies. Mouse OPCs were isolated from the brain of P7 mice through immunopanning with a rat anti-mouse CD140a antibody (BD Biosciences, 558774), recognizing PDGFR $\alpha^{87}$. Cells were plated in 10-cm dishes and kept proliferating in PDGF-AA $(10 \mathrm{ng} / \mathrm{ml})$ and bFGF $(20 \mathrm{ng} / \mathrm{ml})$. The catalytic domain of human TET1 (hTET1CD) was amplified from a template plasmid, pIRES-hrGFP II-TET1_CD (RRID: Addgene_853570 $)^{88}$, and then sub-cloned into the linearized lentiviral vector, pScalps_Puro (RRID:Addgene_99636) ${ }^{89}$, by using In-Fusion cloning system (Takara Bio). The empty lenviral backbone was used as negative control (CTRL). OPCs were transfected with $10 \mu \mathrm{L}$ of CTRL or hTET1-CD lentivirus overnight. After $24 \mathrm{~h}$, media was changed and cells were maintained in proliferative media for 5 days before fixation for immunocytochemistry or collection for qRT-PCR.

Immunocytochemistry. After fixation, cells were incubated in blocking buffer ( $10 \%$ normal goat serum in PBS/Triton $0.3 \%$ ) for $1 \mathrm{~h}$ at room temperature and then incubated overnight at $4{ }^{\circ} \mathrm{C}$ with the primary antibodies diluted in the same blocking buffer. Cells were incubated with the appropriate Alexa Fluor conjugated secondary antibodies for $1 \mathrm{~h}$ at room temperature, then mounted using Fluoromount-G with DAPI.

Primary antibodies used for immunocytochemistry. Primary antibodies used for immunocytochemistry were rat anti-NFM-H (Millipore, MAB5448, 1:500), rabbit anti-NG2 (Millipore, AB5320, 1:200), mouse anti-SLC12A2 (DSHB, T4, 1:100), rat anti-PDGFRa (Millipore, CBL1366, 1:800), rat anti-MBP (Abd Serotec, MCA095, 1:200), mouse anti-MOG (Millipore, MAB5680, 1:500), mouse anti-OLIG2 (Millipore, MABN50, 1:200), rabbit anti-TET1 (Novus Biologicals, NBP1-78966, 1:100).

Secondary antibodies used for immunocytochemistry. Secondary antibodies used for immunocytochemistry were goat anti-rat (IgG 647, Life Technologies, A21247, 1:1,000), goat anti-mouse (IgG 546, Invitrogen, A11030, 1:,1000), goat anti-rabbit (IgG 488, Invitrogen, A11034, 1:1,000), goat anti-rabbit (IgG 546, Invitrogen, A11035, 1:1,000), goat anti-mouse (IgG 488, Invitrogen, A11029, 1:1,000), goat anti-rat (IgG 555, Invitrogen, A21434, 1:1,000).

Immunohistochemisty. For immunohistochemistry, animals were perfused with $4 \%$ paraformaldehyde and post-fixed overnight in the same solution at $4{ }^{\circ} \mathrm{C}$. Brain and spinal cords were dissected, cryo-protected in sucrose solutions, and frozen embedded in OCT. Immunohistochemistry was performed on $12 \mu \mathrm{m}$ cryostat sections. For $5 \mathrm{mC}$ and $5 \mathrm{hmC}$ staining, slides were first permeabilized, denaturalized, and neutralized. Slides were incubated in blocking buffer (5\% normal goat serum in PBS/Triton-X100 0.3\%) for $1 \mathrm{~h}$ at room temperature and then overnight at $4{ }^{\circ} \mathrm{C}$ with the primary antibodies diluted in a similar blocking buffer $(5 \%$ normal goat serum in PBS/Triton-X100 0.3\%). After rinsing with PBS 1X, sections were incubated with the Alexa Fluor secondary antibodies and then washed with PBS 1X. Stained tissue were cover-slipped in DAPI Fluoromount G mounting medium (Thermo Fisher) and examined on a Zeiss LSM800 Fluorescence Microscope. For $5 \mathrm{mC}$ and $5 \mathrm{hmC}$ quantifications, the $5 \mathrm{mC}$ and $5 \mathrm{hmC}$ immunoreactivity of each antibody per nuclear area (pixel $/ \mu \mathrm{m}^{2}$ ) was quantified for at least 50 OLIG $2+$ cells in each technical replicate. We used three technical replicates per biological conditions/ages. Cells were qualified as low $\left(<5 \mathrm{pixel} / \mu \mathrm{m}^{2}\right)$, medium $\left(5-10 \mathrm{pixel} / \mu \mathrm{m}^{2}\right)$ or high $\left(>10 \mathrm{pixel} / \mu \mathrm{m}^{2}\right)$ immunoreactivity relative to OLIG2 nuclear intensity.

Primary antibodies used for immunohistochemistry. Primary antibodies used for immunohistochemistry were Fluoromyelin Green Fluorescent Myelin Stain (Invitrogen, F34651, 1:300), mouse anti-5mC (Abcam, ab10805, 1:200), rabbit anti5hmC (Active Motif, 39769, 1:200), mouse anti-CC1 (Millipore, OP80, 1:200), rat anti-MBP (Abd Serotec, MCA095, 1:200), mouse anti-OLIG2 (Millipore, MABN50, 1:500), rabbit anti-OLIG2 (Santa Cruz, sc48817, 1:200), mouse antiSLC12A2 (DSHB,T4, 1:100), rabbit anti-TET1 (Novus Biologicals, NBP1-78966, 1:100), rabbit anti-TET2 (Epigentek, A-1701, 1:100), rabbit anti-TET3 (Abcam, ab139311, 1:100), rabbit anti-KI67 (Abcam, ab21700, prediluted), mouse antiGFAP (BioLegend, 644701, 1:200), mouse anti-ISLET1 (Abcam, ab86472, 1:200).

Secondary antibodies used for immunohistochemistry. Secondary antibodies used for immunohistochemistry were goat anti-mouse (IgG 488, Invitrogen, A11029, 1:1,000), goat anti-rabbit (IgG 488, Invitrogen, A11034, 1:1,000), goat anti-rabbit (IgG 546, Invitrogen, A11035, 1:1,000), goat anti-mouse (IgG 546, Invitrogen, A11030, 1:,1000), goat anti-rat (IgG 647, Life Technologies, A21247, 1:1,000). 
Electron microscopy. For electron microscopy, animals were perfused at P14 or at P60 at $14 \mathrm{dpl}$ or $21 \mathrm{dpl}$ with $4 \%$ glutaraldehyde in PBS containing $0.4 \mathrm{mM} \mathrm{CaCl} 2$ and post-fixed in the same solution at $4{ }^{\circ} \mathrm{C}$. The spinal cord was coronally sliced at $1 \mathrm{~mm}$ thickness and treated with $2 \%$ osmium tetroxide overnight before being subjected to a standard protocol for epoxy resin embedding. Tissues were sectioned at $1 \mu \mathrm{m}$ and stained with toluidine blue. Ultrathin sections of the lesion site were cut onto copper grids and stained with uranyl acetate before being examined with a Hitachi H-600 transmission electron microscope. Quantification was performed on $50 \mathrm{~nm}$ sections on a minimum of 80 axons per animal, three or four mice for each genotype. G-ratio curves were fit with non-linear regression between control and Tet1 mutant replicates and slopes compared with sum-of-squares F Test.

Immunoelectron microscopy. For immunoelectron microscopy, animals were perfused with $4 \%$ paraformaldehyde and $0.2 \%$ glutaraldehyde in $0.1 \mathrm{M}$ phosphate buffer containing $0.5 \% \mathrm{NaCl}$, as previously described ${ }^{90}$. For immunolabeling, optic nerve sections were incubated with mouse anti-SLC12A2 (DSHB, T4, 1:2,000) in blocking buffer, followed by five washes with PBS and 20 min incubation with protein A-gold $(10 \mathrm{~nm})$ in blocking buffer.

Zebrafish live imaging and single cell labeling. Live imaging of the $\operatorname{Tg}(\mathrm{mbp}$ : EGFP-CAAX) line was carried out using a Zeiss 880 LSM with Airyscan in superresolution mode, using a $20 \mathrm{X}$ objective lens $(\mathrm{NA}=0.8)$. Larvae were embedded in $1.5 \%$ low melting point agarose in embryo medium with tricaine. To mosaically label individual oligodendrocytes in $s l c 12 a 2 b^{u e 58}$ mutants and siblings, we injected one-cell staged embryos with $1 \mathrm{nl}$ of a solution containing $10 \mathrm{ng} / \mu \mathrm{l} \mathrm{pTol} 2-\mathrm{mbp}$ : memScarlet plasmid DNA and $25 \mathrm{ng} / \mu \mathrm{l}$ tol2 transposase mRNA.

Quantification and statistical analysis. Image acquisition was performed on a Zeiss LSM800 Fluorescence Microscope, using ZEN software. Images were analyzed with Fiji-Image J (RRID:SCR_003070). All statistical analyses were done using GraphPad Prism (GraphPad Software, Inc, RRID:SCR_002798). Unpaired Student's $t$ test two-tailed was used for every two datasets with equal variances and for which data follow a normal distribution. One-way and two-way ANOVA was used to compare three or more sets of data. For all graphs, error bars are mean \pm SEM. For all quantifications, $n=3-7$ mice were examined (3-6 images were analyzed and averaged per mouse, for each staining). All statistical details for each graph can be found in the figure legends. qRT-PCR on tissues and single-cells have been replicated twice in independent experiments. All immunostaining on P14 Tet1 mutants and quantifications have been duplicated and evaluated by two independent investigators ${ }^{45,91-93}$.

Reporting summary. Further information on research design is available in the Nature Research Reporting Summary linked to this article.

\section{Data availability}

All data supporting the findings of this study are provided within the paper and its supplementary information. A source data file is provided with this paper. RNA sequencing and Reduced Representation Hydroxymethylation Profiling data from wildtype adult mice have been deposited in NCBI's Gene Expression Omnibus Series accession number GSE122446. RNA sequencing from wild-type and Tet1 mutants during myelin repair accession number GSE137611. Previously published and deposited data used in this study: GSE48872. Lineage specific genes were exported for these microarray data and organized using hierarchical clustering on Multi-experiment Viewer. Further information and requests for resources and reagents should be directed to and will be fulfilled by Dr. Patrizia Casaccia. N.A. Source data are provided with this paper.

Received: 27 February 2020; Accepted: 10 May 2021; Published online: 07 June 2021

\section{References}

1. Franklin, R. J. \& Ffrench-Constant, C. Remyelination in the CNS: from biology to therapy. Nat. Rev. Neurosci. 9, 839-855 (2008).

2. Segel, M. et al. Niche stiffness underlies the ageing of central nervous system progenitor cells. Nature https://doi.org/10.1038/s41586-019-1484-9 (2019).

3. Kang, S. H. et al. Degeneration and impaired regeneration of gray matter oligodendrocytes in amyotrophic lateral sclerosis. Nat. Neurosci. 16, 571-579 (2013).

4. Huynh, J. L. \& Casaccia, P. Epigenetic mechanisms in multiple sclerosis: implications for pathogenesis and treatment. Lancet Neurol. 12, 195-206 (2013).

5. Küspert, M. \& Wegner, M. SomethiNG 2 talk about-transcriptional regulation in embryonic and adult oligodendrocyte precursors. Brain Res. 1638, Part B, 167-182 (2016).
6. Liu, J., Moyon, S., Hernandez, M. \& Casaccia, P. Epigenetic control of oligodendrocyte development: adding new players to old keepers. Curr. Opin. Neurobiol. 39, 133-138 (2016)

7. Bischof, M., Weider, M., Küspert, M., Nave, K.-A. \& Wegner, M. Brg1dependent chromatin remodelling is not essentially required during oligodendroglial differentiation. J. Neurosci. 35, 21-35 (2015).

8. Liu, J. et al. Chromatin landscape defined by repressive histone methylation during oligodendrocyte differentiation. J. Neurosci. 35, 352-365 (2015).

9. Ye, F. et al. HDAC1 and HDAC2 regulate oligodendrocyte differentiation by disrupting the beta-catenin-TCF interaction. Nat. Neurosci. 12, 829-838 (2009).

10. Yu, Y. et al. Olig2 targets chromatin remodelers to enhancers to initiate oligodendrocyte differentiation. Cell 152, 248-261 (2013).

11. Gorkin, D. U., Leung, D. \& Ren, B. The 3D genome in transcriptional regulation and pluripotency. Cell Stem Cell 14, 762-775 (2014).

12. Hernandez, D. G. et al. Distinct DNA methylation changes highly correlated with chronological age in the human brain. Hum. Mol. Genet. 20, 1164-1172 (2011).

13. Huynh, J. L. et al. Epigenome-wide differences in pathology-free regions of multiple sclerosis-affected brains. Nat. Neurosci. 17, 121-130 (2014).

14. Rath, P. C. \& Kanungo, M. S. Methylation of repetitive DNA sequences in the brain during aging of the rat. FEBS Lett. 244, 193-198 (1989).

15. Szulwach, K. E. et al. 5-hmC-mediated epigenetic dynamics during postnatal neurodevelopment and aging. Nat. Neurosci. 14, 1607-1616 (2011).

16. Moyon, S. et al. Functional characterization of DNA methylation in the oligodendrocyte lineage. Cell Rep. https://doi.org/10.1016/j.celrep.2016.03.060 (2016).

17. Shen, S., Liu, A., Li, J., Wolubah, C. \& Casaccia-Bonnefil, P. Epigenetic memory loss in aging oligodendrocytes in the corpus callosum. Neurobiol. Aging 29, 452-463 (2008).

18. Shen, S. et al. Age-dependent epigenetic control of differentiation inhibitors is critical for remyelination efficiency. Nat. Neurosci. 11, 1024-1034 (2008).

19. Moyon, S. et al. Efficient remyelination requires DNA methylation. eNeuro 4. ENEURO 0336-16, 2017 (2017)

20. Horvath, S. DNA methylation age of human tissues and cell types. Genome Biol. 14, R115 (2013)

21. Guo, J. U., Su, Y., Zhong, C., Ming, G. \& Song, H. Hydroxylation of 5methylcytosine by TET1 promotes active DNA demethylation in the adult brain. Cell 145, 423-434 (2011)

22. Hashimoto, H., Zhang, X. \& Cheng, X. Excision of thymine and 5hydroxymethyluracil by the MBD4 DNA glycosylase domain: structural basis and implications for active DNA demethylation. Nucleic Acids Res 40, 8276-8284 (2012)

23. Wu, H. \& Zhang, Y. Mechanisms and functions of Tet protein-mediated 5methylcytosine oxidation. Genes Dev. 25, 2436-2452 (2011).

24. Wu, S. C. \& Zhang, Y. Active DNA demethylation: many roads lead to Rome. Nat. Rev. Mol. Cell Biol. 11, 607-620 (2010).

25. Tahiliani, M. et al. Conversion of 5-methylcytosine to 5 hydroxymethylcytosine in mammalian DNA by MLL partner TET1. Science 324, 930-935 (2009).

26. Kriaucionis, S. \& Heintz, N. The nuclear DNA base 5-hydroxymethylcytosine is present in purkinje neurons and the brain. Science 324, 929-930 (2009).

27. Globisch, D. et al. Tissue distribution of 5-hydroxymethylcytosine and search for active demethylation intermediates. PLoS One 5, e15367 (2010).

28. Zhao, X. et al. Dynamics of ten-eleven translocation hydroxylase family proteins and 5-hydroxymethylcytosine in oligodendrocyte differentiation. Glia 62, 914-926 (2014).

29. Hahn, M. A. et al. Dynamics of 5-hydroxymethylcytosine and chromatin marks in mammalian neurogenesis. Cell Rep. 3, 291-300 (2013).

30. Weng, Y.-L. et al. An intrinsic epigenetic barrier for functional axon regeneration. Neuron 94, e6 (2017).

31. Zhu, X. et al. Role of Tet1/3 genes and chromatin remodeling genes in cerebellar circuit formation. Neuron 89, 100-112 (2016).

32. Takai, H. et al. 5-Hydroxymethylcytosine plays a critical role in glioblastomagenesis by recruiting the CHTOP-methylosome complex. Cell Rep. 9, 48-60 (2014).

33. Gilson, J. \& Blakemore, W. F. Failure of remyelination in areas of demyelination produced in the spinal cord of old rats. Neuropathol. Appl Neurobiol. 19, 173-181 (1993).

34. Hampton, D. W. et al. Focal immune-mediated white matter demyelination reveals an age-associated increase in axonal vulnerability and decreased remyelination efficiency. Am. J. Pathol. 180, 1897-1905 (2012).

35. Ruckh, J. M. et al. Rejuvenation of regeneration in the aging central nervous system. Cell Stem Cell 10, 96-103 (2012).

36. Shields, S. A., Gilson, J. M., Blakemore, W. F. \& Franklin, R. J. Remyelination occurs as extensively but more slowly in old rats compared to young rats following gliotoxin-induced CNS demyelination. Glia 28, 77-83 (1999).

37. Franklin, R. J. M., Zhao, C. \& Sim, F. J. Ageing and CNS remyelination. Neuroreport 13, 923-928 (2002). 
38. Moyon, S. et al. Demyelination causes adult CNS progenitors to revert to an immature state and express immune cues that support their migration. J. Neurosci. 35, 4-20 (2015).

39. $\mathrm{Lu}, \mathrm{Q}$. R. et al. Common developmental requirement for Olig function indicates a motor neuron/oligodendrocyte connection. Cell 109, 75-86 (2002).

40. Towers, A. J. et al. Epigenetic dysregulation of Oxtr in Tet1-deficient mice has implications for neuropsychiatric disorders. JCI Insight 3, e120592 (2018).

41. Moran-Crusio, K. et al. Tet2 loss leads to increased hematopoietic stem cell self-renewal and myeloid transformation. Cancer Cell 20, 11-24 (2011)

42. Kang, S. H., Fukaya, M., Yang, J. K., Rothstein, J. D. \& Bergles, D. E. NG2+ $\mathrm{CNS}$ glial progenitors remain committed to the oligodendrocyte lineage in postnatal life and following neurodegeneration. Neuron 68, 668-681 (2010).

43. Le Bras, B. et al. Oligodendrocyte development in the embryonic brain: the contribution of the plp lineage. Int J. Dev. Biol. 49, 209-220 (2005).

44. Klinghoffer, R. A., Hamilton, T. G., Hoch, R. \& Soriano, P. An allelic series at the PDGFalphaR locus indicates unequal contributions of distinct signaling pathways during development. Dev. Cell 2, 103-113 (2002).

45. Spassky, N. et al. Multiple restricted origin of oligodendrocytes. J. Neurosci. 18, 8331-8343 (1998).

46. Zonouzi, M. et al. GABAergic regulation of cerebellar NG2 cell development is altered in perinatal white matter injury. Nat. Neurosci. 18, 674-682 (2015).

47. Zhang, Y. et al. An RNA-sequencing transcriptome and splicing database of glia, neurons, and vascular cells of the cerebral cortex. J. Neurosci. Off. J. Soc. Neurosci. 34, 11929-11947 (2014).

48. Zeisel, A. et al. Cell types in the mouse cortex and hippocampus revealed by single-cell RNA-seq. Science https://doi.org/10.1126/science.aaa1934 (2015).

49. Marques, S. et al. Oligodendrocyte heterogeneity in the mouse juvenile and adult central nervous system. Science 352, 1326-1329 (2016).

50. Tasic, B. et al. Adult mouse cortical cell taxonomy revealed by single cell transcriptomics. Nat. Neurosci. advance online publication, (2016).

51. Sharma, K. et al. Cell type- and brain region-resolved mouse brain proteome. Nat. Neurosci. https://doi.org/10.1038/nn.4160 (2015).

52. Marshall-Phelps, K. L. H. et al. Neuronal activity disrupts myelinated axon integrity in the absence of NKCC1b. J. Cell Biol. 219, e201909022 (2020).

53. He, Y., Sandoval, J. \& Casaccia-Bonnefil, P. Events at the transition between cell cycle exit and oligodendrocyte progenitor differentiation: the role of HDAC and YY1. Neuron Glia Biol. 3, 221-331 (2007).

54. Scaglione, A. et al. PRMT5-mediated regulation of developmental myelination. Nat. Commun. 9, 2840 (2018).

55. Chari, D. M., Crang, A. J. \& Blakemore, W. F. Decline in rate of colonization of oligodendrocyte progenitor cell (OPC)-depleted tissue by adult OPCs with age. J. Neuropathol. Exp. Neurol. 62, 908-916 (2003).

56. Dawson, M. R., Polito, A., Levine, J. M. \& Reynolds, R. NG2-expressing glial progenitor cells: an abundant and widespread population of cycling cells in the adult rat CNS. Mol. Cell Neurosci. 24, 476-488 (2003).

57. Fernandez-Castaneda, A. \& Gaultier, A. Adult oligodendrocyte progenitor cells-multifaceted regulators of the CNS in health and disease. Brain. Behav. Immun. 57, 1-7 (2016).

58. Gensert, J. M. \& Goldman, J. E. Heterogeneity of cycling glial progenitors in the adult mammalian cortex and white matter. J. Neurobiol. 48, 75-86 (2001).

59. Nishiyama, A., Lin, X. H., Giese, N., Heldin, C. H. \& Stallcup, W. B. Colocalization of NG2 proteoglycan and PDGF alpha-receptor on O2A progenitor cells in the developing rat brain. J. Neurosci. Res. 43, 299-314 (1996).

60. Nishiyama, A., Chang, A. \& Trapp, B. D. NG2+ glial cells: a novel glial cell population in the adult brain. J. Neuropathol. Exp. Neurol. 58, 1113-1124 (1999).

61. Wolswijk, G. \& Noble, M. Identification of an adult-specific glial progenitor cell. Development 105, 387-400 (1989).

62. Lin, G., Mela, A., Guilfoyle, E. \& Goldman, J. Neonatal and adult O4(+) oligodendrocyte lineage cells display different growth factor responses and different gene expression patterns. J. Neurosci. Res. 87, 3390-3402 (2009).

63. Mellén, M., Ayata, P., Dewell, S., Kriaucionis, S. \& Heintz, N. MeCP2 binds to $5 \mathrm{hmC}$ enriched within active genes and accessible chromatin in the nervous system. Cell 151, 1417-1430 (2012).

64. Lister, R. et al. Global epigenomic reconfiguration during mammalian brain development. Science 341, 1237905 (2013).

65. Song, C.-X. et al. Selective chemical labeling reveals the genome-wide distribution of 5-hydroxymethylcytosine. Nat. Biotechnol. 29, 68-72 (2011).

66. Zhang, W. et al. Isoform switch of TET1 regulates DNA demethylation and mouse development. Mol. Cell 64, 1062-1073 (2016).
67. Zhang, P. et al. Methyl-CpG binding domain protein 1 regulates localization and activity of Tet1 in a CXXC3 domain-dependent manner. Nucleic Acids Res. 45, 7118-7136 (2017).

68. Kaila, K., Price, T. J., Payne, J. A., Puskarjov, M. \& Voipio, J. Cation-chloride cotransporters in neuronal development, plasticity and disease. Nat. Rev. Neurosci. 15, 637-654 (2014).

69. Blaesse, P., Airaksinen, M. S., Rivera, C. \& Kaila, K. Cation-chloride cotransporters and neuronal function. Neuron 61, 820-838 (2009).

70. Jantzie, L. L. et al. Chloride cotransporter NKCC1 inhibitor bumetanide protects against white matter injury in a rodent model of periventricular leukomalacia. Pediatr. Res. 77, 554-562 (2015).

71. Yu, Y. et al. NKCC1 inhibition attenuates chronic cerebral hypoperfusioninduced white matter lesions by enhancing progenitor cells of oligodendrocyte proliferation. J. Mol. Neurosci. 64, 449-458 (2018).

72. Haas, M. \& Forbush, B. The Na-K-Cl cotransporter of secretory epithelia. Annu. Rev. Physiol. 62, 515-534 (2000).

73. Hamann, S., Herrera-Perez, J. J., Zeuthen, T. \& Alvarez-Leefmans, F. J. Cotransport of water by the $\mathrm{Na}+-\mathrm{K}+-2 \mathrm{Cl}-$ cotransporter NKCC1 in mammalian epithelial cells. J. Physiol. 588, 4089-4101 (2010).

74. Zhang, J. et al. Functional kinomics establishes a critical node of volumesensitive cation- $\mathrm{Cl}-$ cotransporter regulation in the mammalian brain. Sci. Rep. 6, 35986 (2016).

75. Zhang, J. et al. Modulation of brain cation-Cl - cotransport via the SPAK kinase inhibitor ZT-1a. Nat. Commun. 11, 78 (2020).

76. Abbas, L. \& Whitfield, T. T. Nkccl (Slc12a2) is required for the regulation of endolymph volume in the otic vesicle and swim bladder volume in the zebrafish larva. Development 136, 2837-2848 (2009).

77. Cullen, C. L. et al. Periaxonal and nodal plasticities modulate action potential conduction in the adult mouse brain. Cell Rep. 34, 108641 (2021).

78. Chomyk, A. M. et al. DNA methylation in demyelinated multiple sclerosis hippocampus. Sci. Rep. 7, 8696 (2017).

79. Dawlaty, M. M. et al. Tet1 is dispensable for maintaining pluripotency and its loss is compatible with embryonic and postnatal development. Cell Stem Cell 9, 166-175 (2011)

80. Fancy, S. P. et al. Dysregulation of the Wnt pathway inhibits timely myelination and remyelination in the mammalian CNS. Genes Dev. 23, 1571-1585 (2009).

81. Anders, S. \& Huber, W. Differential expression analysis for sequence count data. Genome Biol. 11, R106 (2010).

82. Eden, E., Navon, R., Steinfeld, I., Lipson, D. \& Yakhini, Z. GOrilla: a tool for discovery and visualization of enriched GO terms in ranked gene lists. BMC Bioinform. 10, 48 (2009).

83. Kuleshov, M. V. et al. Enrichr: a comprehensive gene set enrichment analysis web server 2016 update. Nucleic Acids Res 44, W90-W97 (2016).

84. Supek, F., Bošnjak, M., Škunca, N. \& Šmuc, T. REVIGO summarizes and visualizes long lists of gene ontology terms. PLoS One 6, e21800 (2011).

85. Petterson, A., Chung, T. H., Tan, D., Sun, X. \& Jia, X.-Y. RRHP: a tag-based approach for 5-hydroxymethylcytosine mapping at single-site resolution. Genome Biol. 15, 456 (2014).

86. Sun, X., Chung, T. H., Tan, D. \& Kim, A. Practical guidelines and consideration of using RRHP for 5hmC detection. Epigenomics 8, 225-235 (2016).

87. Cahoy, J. D. et al. A transcriptome database for astrocytes, neurons, and oligodendrocytes: a new resource for understanding brain development and function. J. Neurosci. 28, 264-278 (2008).

88. Jin, C. et al. TET1 is a maintenance DNA demethylase that prevents methylation spreading in differentiated cells. Nucleic Acids Res. 42, 6956-6971 (2014).

89. Montagner, S. et al. TET2 regulates mast cell differentiation and proliferation through catalytic and non-catalytic activities. Cell Rep. 15, 1566-1579 (2016).

90. Werner, H. B. et al. Proteolipid protein is required for transport of sirtuin 2 into CNS myelin. J. Neurosci. 27, 7717-7730 (2007).

91. Wolswijk, G., Riddle, P. N. \& Noble, M. Platelet-derived growth factor is mitogenic for O-2Aadult progenitor cells. Glia 4, 495-503 (1991).

92. Song, S., Luo, L., Sun, B. \& Sun, D. Roles of glial ion transporters in brain diseases. Glia 68, 472-494 (2020).

93. Wang, H., Yan, Y., Kintner, D. B., Lytle, C. \& Sun, D. GABA-mediated trophic effect on oligodendrocytes requires $\mathrm{Na}-\mathrm{K}-2 \mathrm{Cl}$ cotransport activity. $J$. Neurophysiol. 90, 1257-1265 (2003).

\section{Acknowledgements}

This work was supported by R35 NS111604-01 and NMSS-RG4890A10 to PC, postdoctoral fellowships from the Paralyzed Veterans of America (3061) and from National Multiple Sclerosis Society (FG-1507-04996) to SM. BS was funded through 
the Cluster of Excellence and DFG Research Center Nanoscale Microscopy and Molecular Physiology of the Brain. Work in the Lyons lab was supported by Wellcome Trust Senior Research Fellowships (102836/Z/13/Z and 214244/Z/18/Z) and by a project grant from the Multiple Sclerosis Society (95). We thank the Flow Cytometry Core CyPS (Pierre \& Marie Curie University, Pitié-Salpêtrière Hospital, Paris, France) for help on sorting adult OPC and adult OL used for sequencing, the Epigenomic Core at the ASRC-CUNY for OPC sorting and C1/Biomark experiments, the Epigenomics Core at Weill Cornell for sequencings and the NYU EM Core for electron microscopy on LPC tissues. We would like to thank the Casaccia lab members for fruitful discussions.

\section{Author contributions}

Data acquisition, S.M., R.F., K.M.P., L.K., S.B., D.M., D.H., B.S., D.A.L., W.M.; Experimental design, validation, data analysis, visualization, original draft, S.M.; Conceptualization, writing, revisions, and editing, S.M. and P.C.; Funding acquisition, supervision, P.C.; Resources, Y.H.J.

\section{Competing interests}

The authors declare no competing interests.

\section{Additional information}

Supplementary information The online version contains supplementary material available at https://doi.org/10.1038/s41467-021-23735-3.

Correspondence and requests for materials should be addressed to S.M. or P.C.

Peer review information Nature Communications thanks the anonymous reviewer(s) for their contribution to the peer review of this work. Peer reviewer reports are available.

Reprints and permission information is available at http://www.nature.com/reprints

Publisher's note Springer Nature remains neutral with regard to jurisdictional claims in published maps and institutional affiliations.

(c) (i) adaptation, distribution and reproduction in any medium or format, as long as you give appropriate credit to the original author(s) and the source, provide a link to the Creative Commons license, and indicate if changes were made. The images or other third party material in this article are included in the article's Creative Commons license, unless indicated otherwise in a credit line to the material. If material is not included in the article's Creative Commons license and your intended use is not permitted by statutory regulation or exceeds the permitted use, you will need to obtain permission directly from the copyright holder. To view a copy of this license, visit http://creativecommons.org/ licenses/by/4.0/.

(C) The Author(s) 2021 